\title{
Rheumatic “Taussig-Bing Heart": A Case Report
}

\author{
Ramachandran Muthiah \\ Thoothukudi Medical College Hospital, Thoothukudi, India \\ Email: cardioramachandran@yahoo.co.uk
}

How to cite this paper: Muthiah, R. (2018) Rheumatic "Taussig-Bing Heart": A Case Report. Case Reports in Clinical Medicine, 7, 7-36.

https://doi.org/10.4236/crcm.2018.71002

Received: December 3, 2017

Accepted: January 8, 2018

Published: January 11, 2018

Copyright $\odot 2018$ by author and Scientific Research Publishing Inc. This work is licensed under the Creative Commons Attribution International License (CC BY 4.0).

http://creativecommons.org/licenses/by/4.0/ Open Access

\begin{abstract}
Aim: To report a case of acyanotic Taussig-Bing heart, anatomically consistent with L-transposition and rheumatic Left AV valve regurgitation associated with complete AV block in an adolescent male. Introduction: TaussigBing heart is one of the conotruncal malformation, characterized by doubleoutlet right ventricle (DORV) and a subpulmonary VSD. Embryologically, abnormal cardiac looping with malalignment of conotruncal septum result its complexity and great artery relationships. Case Report: A 14-year old acyanotic boy presented with severe left-sided AV valve regurgitation and bradycardia. ECG revealed left sided morphologic right ventricular hypertrophy (RVH) as evidenced by a loss of septal Q waves in left precordial leads suggesting ventricular inversion. X-ray chest revealed a straight upper right cardiac border due to loss of normal relationship of great vessels and cardiomegaly due to both left atrial and morphologic right ventricular enlargements suggesting a left-sided regurgitant lesion. Echocardiography revealed the ventricular inversion, primary origin of both L-transposed great arteries from the left-sided morphologic right ventricle suggesting a "double-outlet morphologic right ventricle" with "double discordance" and a subpulmonary VSD of Taussig-Bing type. The left-sided morphologic tricuspid valve is severely regurgitant due to rheumatic process resulting in heart failure which was improved with anti-failure measures and penicillin prophylaxis. Conclusion: The presence of left-sided regurgitation associated with bradycardia is a suspicion of "double discordance" and "double switch" procedure remains the mainstay of its surgical correction. Left AV valve replacement with intraventricular repair is preferred in this child since the malformation is consistent with Taussing-Bing type of DORV with L-transposition.
\end{abstract}

\section{Keywords}

Double-Outlet Right Ventricle, Ventricular Inversion, Subpulmonary VSD, L-Transposition, Left-Sided Ebstein's Anomaly 


\section{Introduction}

"Taussig-Bing heart" is a morphological subtype of double-outlet right ventricle (DORV) with subpulmonary VSD (ventricular septal defect) [1]. It was first described in 1949 by two outstanding physicians, Helen Brooke Taussig and Richard John Bing, who worked together at the John Hopkins Hospital in Baltimore. The original "Taussig-Bing heart" [2] may be summarized as a double-outlet right ventricle (DORV) with semilunar valves side-by-side and approximately at the same height, a bilateral conus, and a subpulmonary VSD. This original description has been broadened to include all kinds of double-outlet right ventricle with subpulmonary VSD [3] [4]. The morphological variability of "Taussig-Bing heart" is guided by the relationship between great arteries [5] and ventricles that are associated with a bilateral conus [6] [7] and so this case had been reported.

\section{Case Report}

A 14-year old boy was admitted with features of heart failure in the intensive care unit. His pulse rate was $50 \mathrm{bpm}$ and blood pressure 110/70 $\mathrm{mmHg}$. He had a history of rheumatic fever during childhood and blood chemistry revealed a positive ASO (anti-streptolysin O) titer. Auscultation revealed a grade 4/6 pansystolic murmur over the cardiac apex with a shift of apical impulse to left $6^{\text {th }}$ space towards axilla. ECG revealed high-grade AV block with features of ventricular inversion and strain pattern due to morphologic RVH as shown in Figure 1 and Figure 2, compared to a normal right-sided pattern as in Figure 3 with normal echocardiography as in Figure 4 of a normal adolescent male of similar age. X-ray chest revealed a narrow vascular pedicle with left atrial and morphologic right ventricular enlargement as shown in Figure 5. Transthoracic echocardiography revealed a VSD with inlet extension as in Figure 6 and a discordant relationship between atria and ventricles and a left-sided Ebstenoid morphologic tricuspid valve as shown in Figure 7 (apical four chamber view), but mTV (morphologic tricuspid valve) is normally attached as in Figure 8 and Figure 9 (subcostal views). The leaflets are showing the features of rheumatic etiology as in Figures 10-14 and severely regurgitant as shown in Figures 15-18.

The child was treated with anti-failure medications such as diuretics, angiotensin-converting enzyme inhibitors (enalapril) with penicillin prophylaxis for a period of one and a half months and the regurgitant lesion became decreased as shown in Figure 19 and Figure 20 and M-mode mRV study showing the marked improvement in ejection fraction from $36 \%$ to $46 \%$ as shown in Figure 21 and Figure 22.

Since the great arteries are primarily originating from morphologic RV as in Figure 23 and it is L-transposed with side-by-side relationship as in Figure 24 with a subpulmonary VSD, it is consistent with Taussig-Bing anomaly of Ltransposition, a Kawashima intraventricular repair was advised if further deterioration of $\mathrm{mRV}$ function occurs on periodic follow-up with a continuation of 


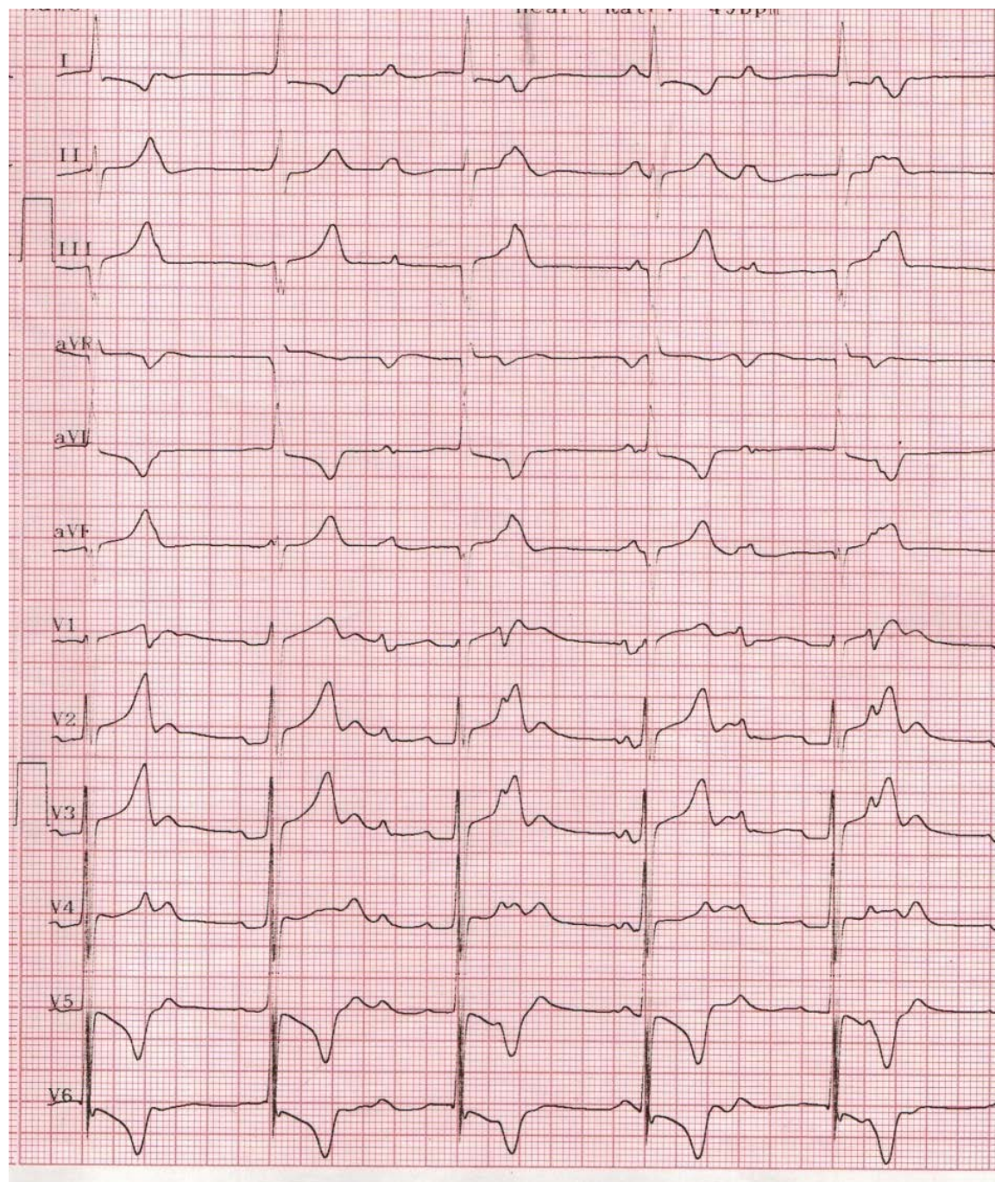

Figure 1. ECG showing complete AV block with narrow QRS (QRS duration < $120 \mathrm{~ms}$ ) complexes and a heart rate of $50 \mathrm{bpm}$ suggesting a congenital high grade AV block. There is a "strain" pattern in $\mathrm{L} 1, \mathrm{aVL}, \mathrm{V}_{5}-\mathrm{V}_{6}$ with left axis deviation, absence of septal Q waves in left precordial leads due to inversion of bundle branches (reversal of septal depolarization) with a hypertrophied morphologic RV on the left side in a 14-year old boy.

medical treatment along with lifelong penicillin prophylaxis. Palliative procedures are not indicated in this boy since there is no aortic arch obstruction and outflow tract lesions as shown in Figure 25 and Figure 26.

\section{Discussion}

\subsection{Review of Literature}

Taussig-Bing suspected a totally different malformation at autopsy in a five and a half year old girl who had cyanosis since birth and died during angiocardiography after a third intravenous injection of contrast material, the diodrast, the child sat bolt upright and the heart stopped. The malformation consists of a transposed aorta, a large pulmonary artery which arises primarily from the right 


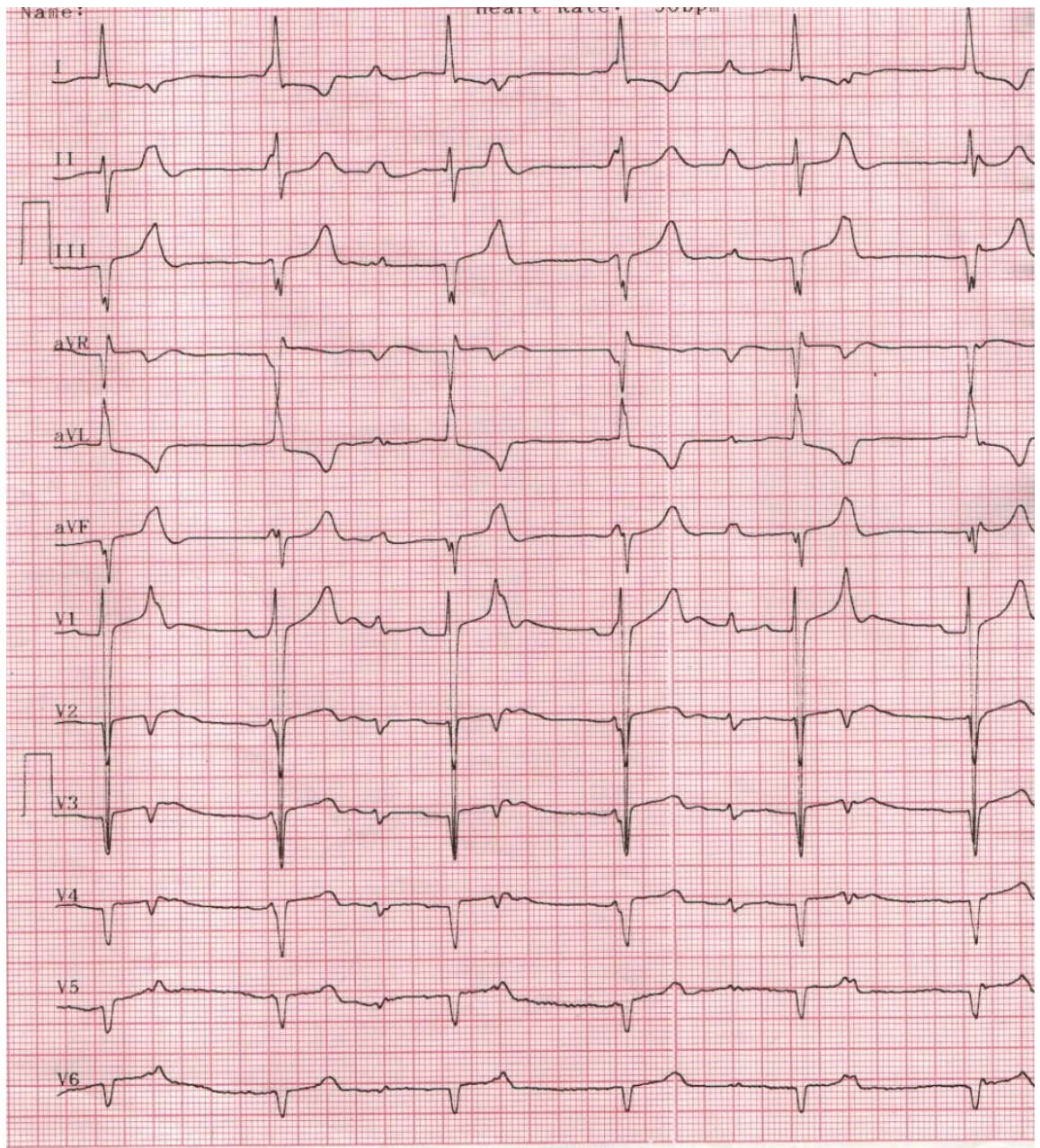

Figure 2. ECG showing the QS complexes in inferior leads (III, aVF) and a QS pattern in right-sided chest leads $\left(\mathrm{V}_{2}-\mathrm{V}_{6}\right)$, compared to a normal ECG of right-sided leads in the same age of a male boy as in Figure 3.

ventricle and partially overrides the ventricular septum, a high ventricular septal defect, and right ventricular hypertrophy. Maurice Lev was one of the first to call this anomaly as "Taussig-Bing syndrome" [8].

This anomaly was initially described in 1949 by Taussig and Bing as transposition of the great arteries. The important difference between Taussig-Bing anomaly and transposition of the great arteries were described by Richard Van Praagh in his editorial review and stressed that the absence of pulmonary-mitral continuity is the characteristic feature of this anomaly. Taussig and Bing emphasized that the overriding of pulmonary artery was an integral part of this malformation. This anomaly was eventually named as "Taussig-Bing heart" in 1950 by Lev and associates [9] and subsequently introduced the spectrum of TaussigBing hearts depending on the degree of pulmonary artery overriding (rightsided, intermediate, and left sided) [10]. The deviation of infundibular septum as a fundamental requisite to define these hearts, collectively termed as "Taussig-Bing complex". 


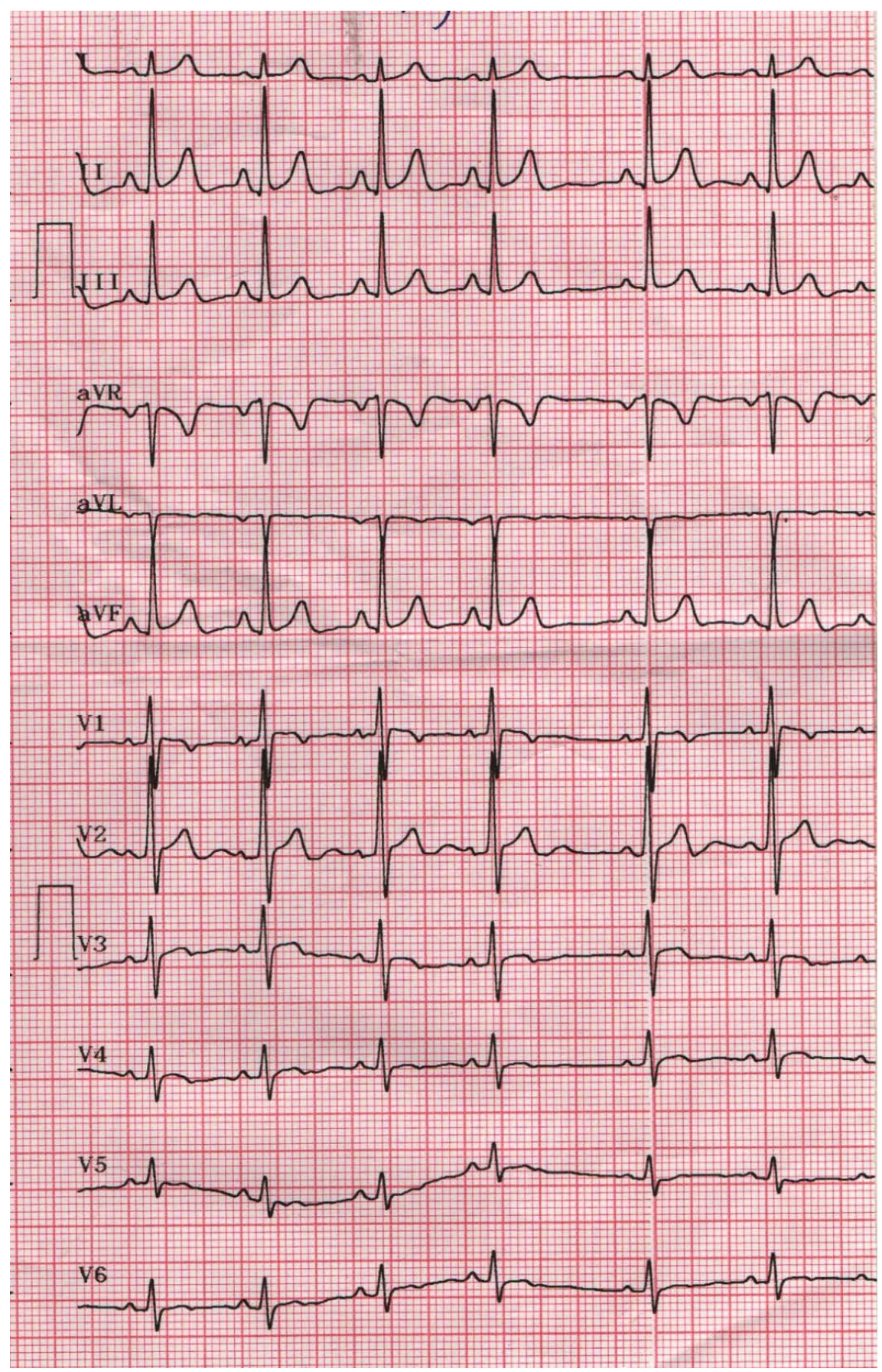

Figure 3. ECG showing RS complexes in the right sided leads $\left(\mathrm{V}_{1}-\mathrm{V}_{3}\right)$ and QRS pattern in $\mathrm{V}_{4}-\mathrm{V}_{6}$ of a normal 14-year old boy.

\subsection{Etiopathogenesis}

The Taussig-Bing anomaly is relatively rare and it accounted for approximately $8 \%$ of cases in Sridaromont series [11]. In these cases, the pulmonary stenosis does not occur, the pulmonary trunk is markedly dilated as in Figure 25 and there is a high VSD immediately subjacent to the pulmonary valve (subpulmonary) and the pulmonary valve is not in continuity with AV (atrioventricular) 


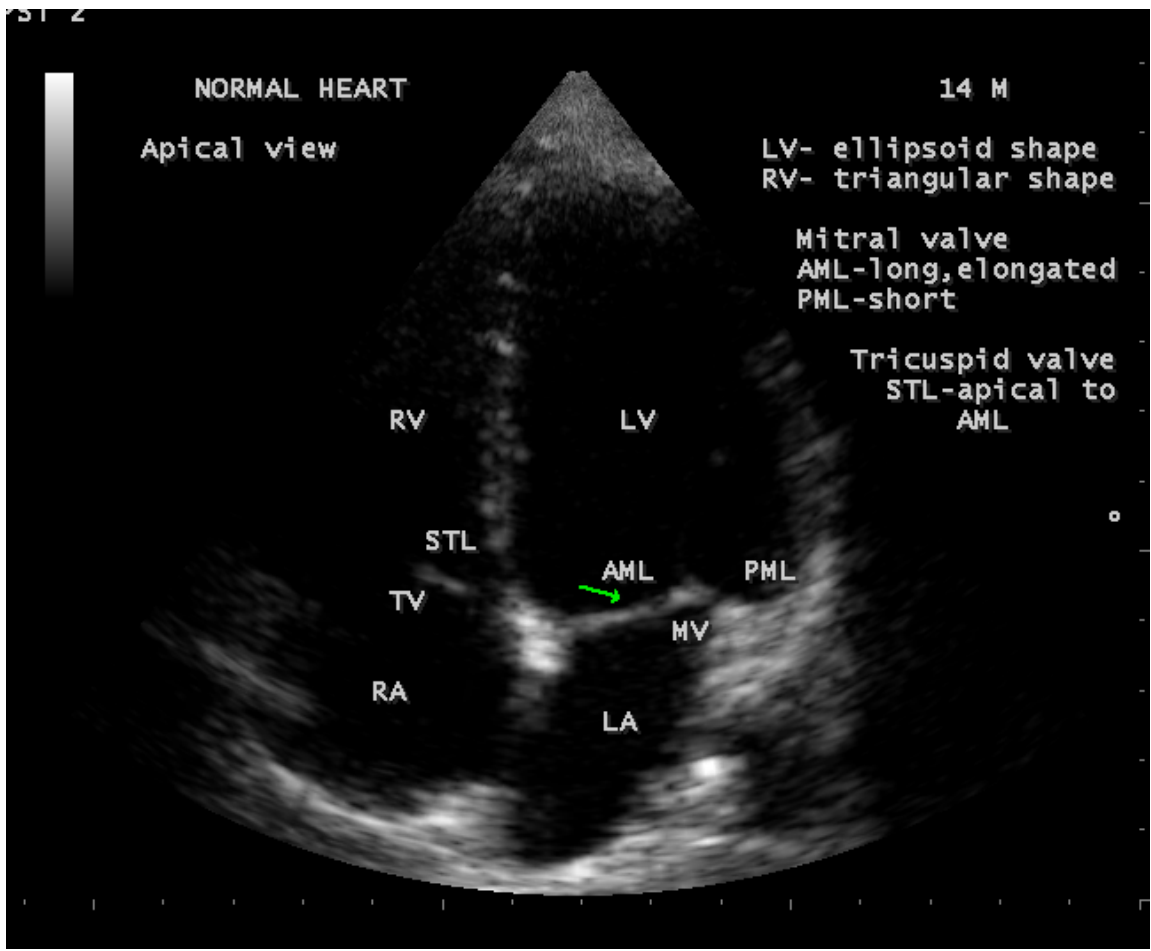

Figure 4. Apical view showing the normal atrioventricular relationships, AV valves (mitral and tricuspid) attachments and the shape of ventricles in a normal 14-year old boy. AML (anterior mitral leaflet) is long and elongated (arrow) as a feature of mitral valve.

valve because of interposed subpulmonary conal free wall musculature as in Figure 14. The anatomic feature of Taussig-Bing malformation appears to result from marked and symmetrical development of both conal free walls. The semilunar valves have been protruded anteriorly to about the same extent by the underlying conal musculature and remain side-by-side, so that both great arteries arise above the anterior (right) ventricle and the failure of complete absorption of the conus or coni result in fibrous discontinuity with atrioventricular valves.

During the development of the heart, the outflow regions initially remain exclusively with the primitive right ventricle and undergo extensive remodeling to ventricle appears to represent a primitive embryologic condition as failure to achieve conotruncal inversion and leftward shift of conus results in persistence divide into aorta and pulmonary artery with connection to left and right ventricles respectively. Goor and Edwards [12] stated that double-outlet right of this condition with complete origin of both great arteries from the morphologic right ventricle. The primitive cardiac tube anchored at one end by the sinus venosus and at the other end by conus arteriosus. The chambers of the heart develop by ballooning from the primary heart tube as atrial appendage ballooning in parallel to the atrial component of the tube and the apical component of the ventricle balloons in series from the inlet and outlet parts of the ventricular loop. The "looping" of the straight heart tube during the $3^{\text {rd }}$ week of gestation is one of the key embryologic process leading to anatomic alignment of chambers of the 


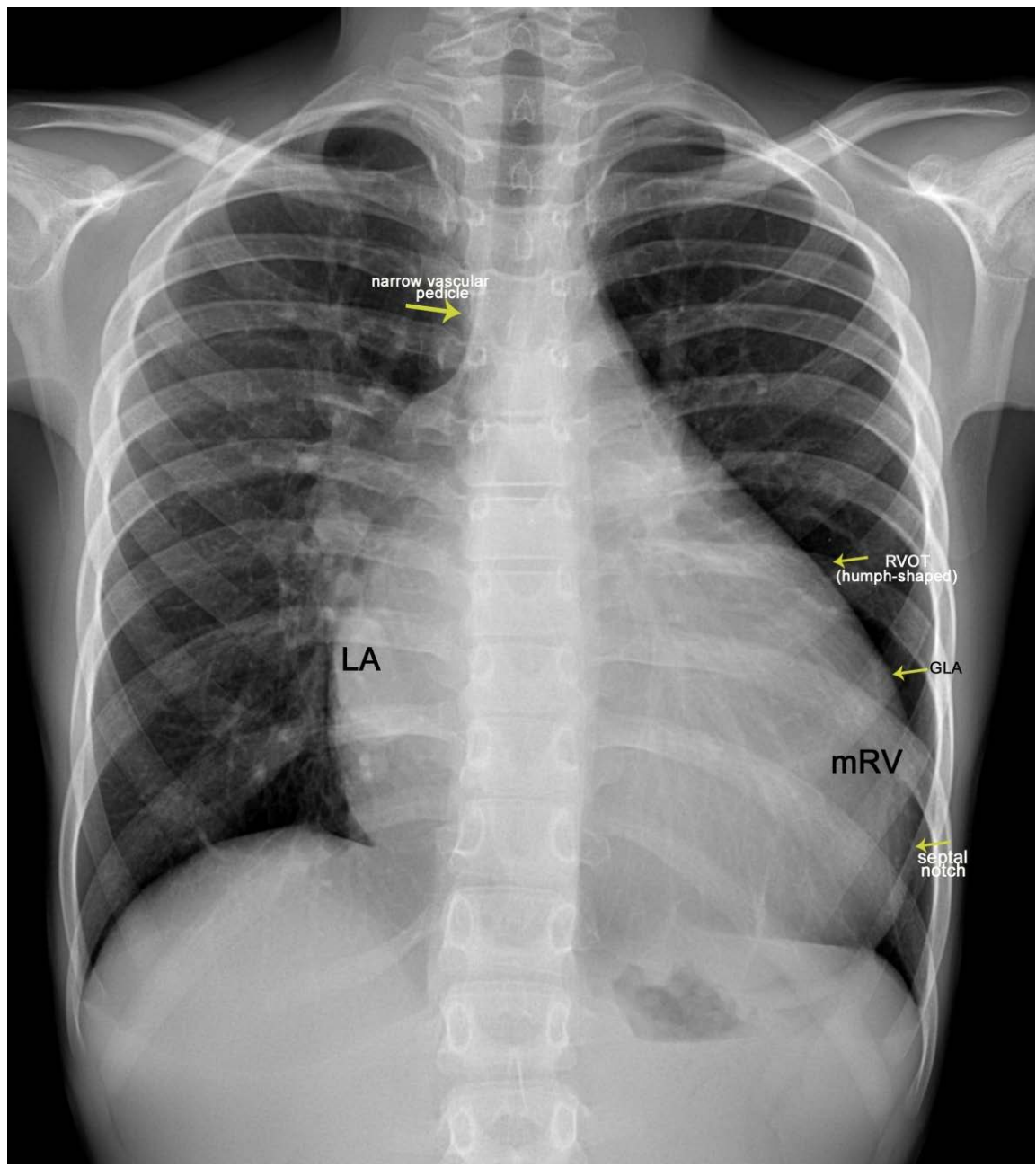

Figure 5. X-ray chest (postero-anterior) view showing the narrow vascular pedicle (right upper arrow) since great arteries are not border forming, appears straight due to loss of normal relationship between arterial trunks as ascending aorta is typically not visualized on the right side, convexities from descending aortic knob and pulmonary trunk are absent on the left side due to posteriorly positioned pulmonary artery suggesting L-transposition. The cardiomegaly is due to aneurysmal Left atrial (LA) enlargement and a dilated morphologic right ventricle $(\mathrm{mRV})$. The visceral situs is normal. Left upper arrow-"hump-shaped" due to inverted RV infundibulum. Left middle arrow-giant left atrium (GLA). Left lower arrow- "septal notch" corresponding to apical position of interventricular groove.

heart and it normally "loops" to the right (D-loop) resulting in normal morphological position of right ventricle to the right side. The abnormal cardiac looping to the left side (L-loop) brings the morphologic right ventricle to the left and the ventricles are reversed (ventricular inversion), the atrioventricular valves "follow" the ventricles and the two great arteries are transposed or exit from the "wrong" ventricle, but the systemic venous blood flows from the morphologic left ventricle to the pulmonary artery and the systemic arterial blood flows from the morphologic right ventricle to the aorta and so the circulation is corrected. Thus, during embryologic development, left-handed looping of the heart tube 


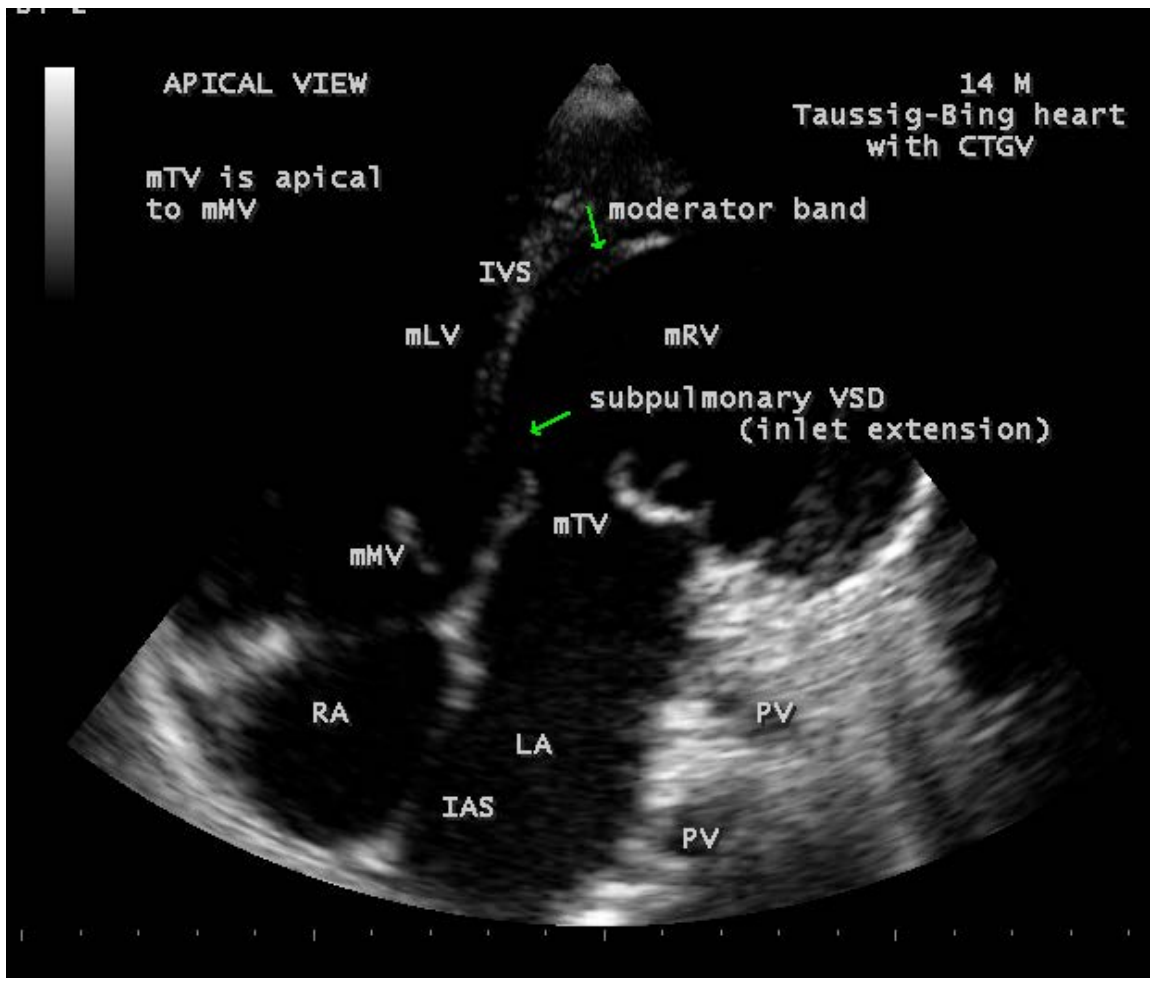

Figure 6. Apical view showing the VSD (ventricular septal defect) with inlet extension (lower arrow) and a moderator band (upper arrow).

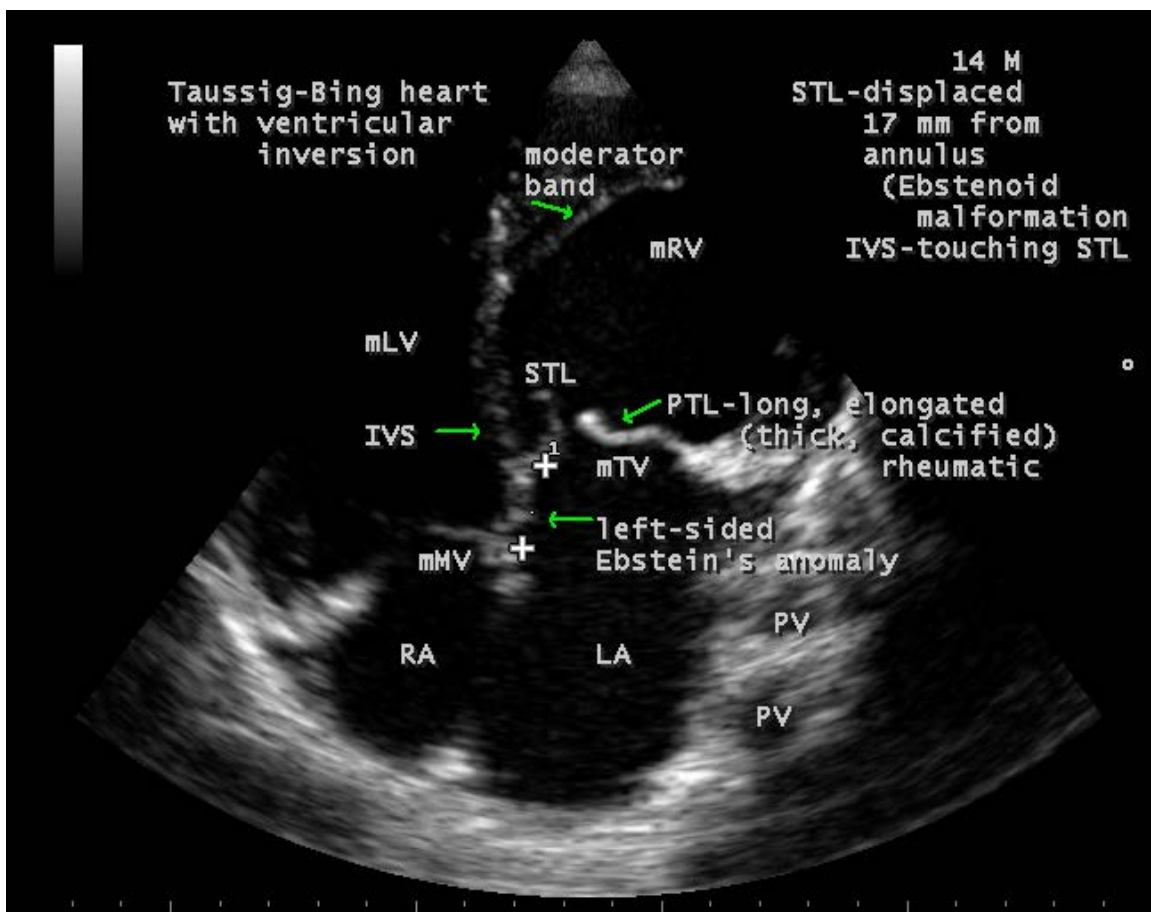

Figure 7. Apical view showing the "Ebstenoid malformation" of left-sided morphologic tricuspid valve (mTV) (left lower arrow) due to adherence of septum (IVS) to STL (right arrow). The mTV is identified by a long and elongated posterior leaflet (left middle arrow) which is short in mitral valve as in Figure 4 of a normal 14-year old boy and a discordant AV connection. 


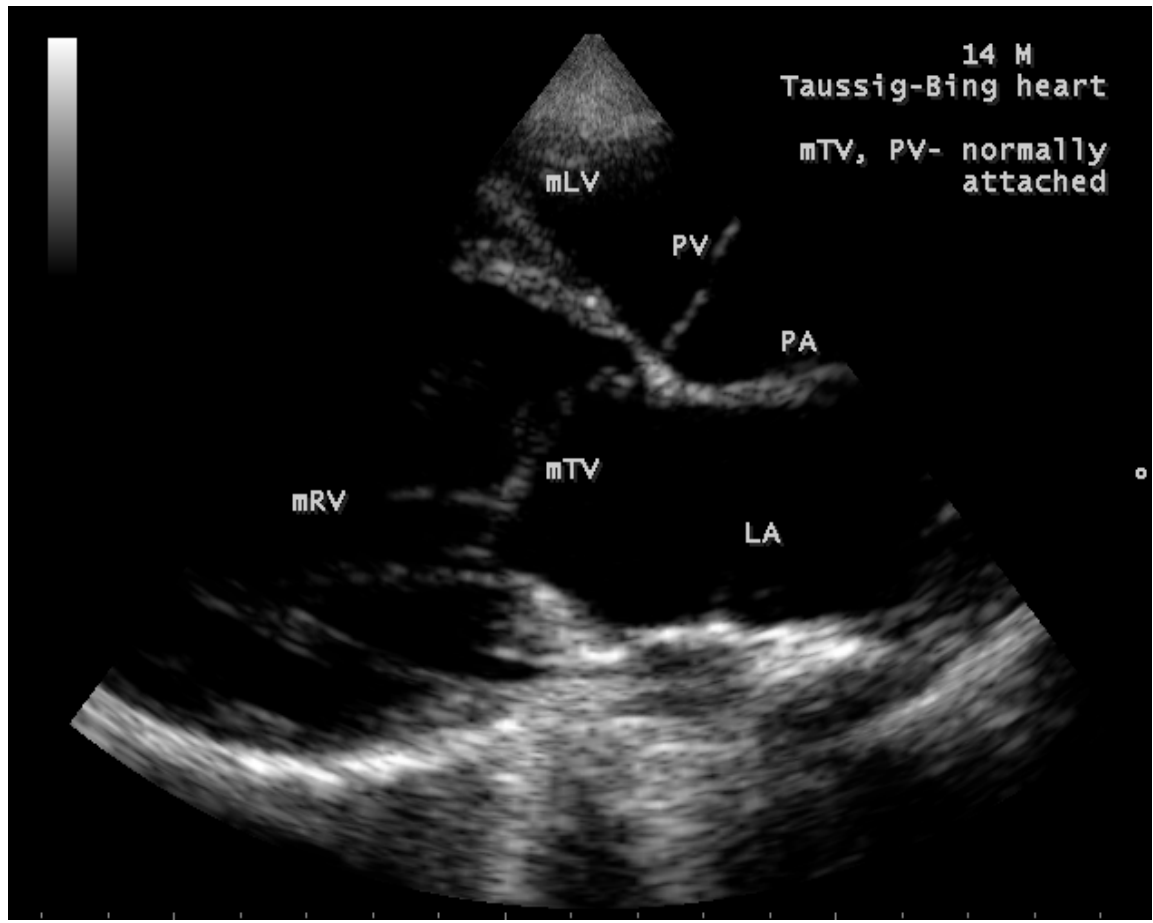

Figure 8. Subcostal view showing the normally attached rheumatic morphologic tricuspid valve and the pulmonary valve.

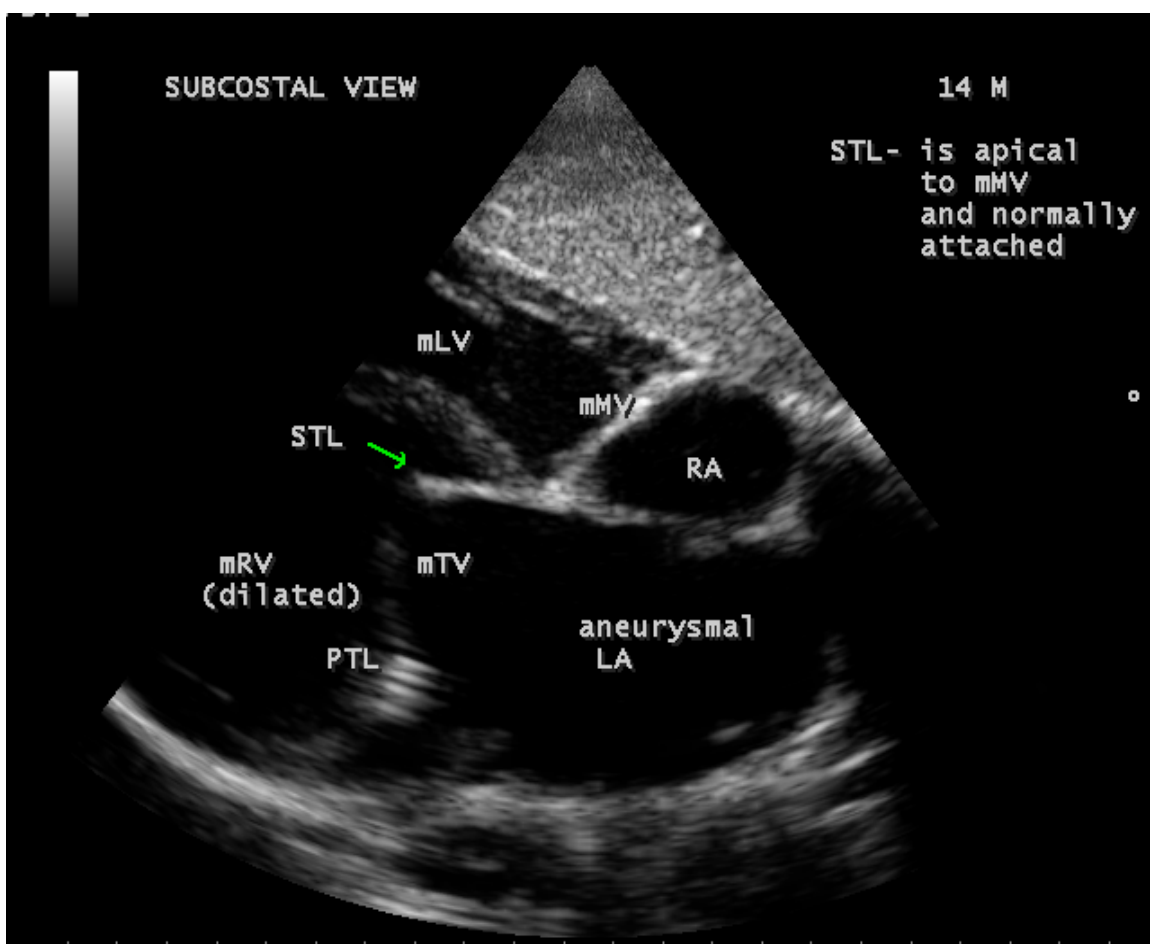

Figure 9. Subcostal view showing the normal attachments of morphologic tricuspid (mTV) (arrow) and mitral valves (mMV) to the annulus. STL-septal tricuspid leaflet.

results in AV (atrioventricular) discordance and the aorto-pulmonary septum fails to rotate $180^{\circ}$, resulting in ventriculo-arterial discordance. This heart defect 


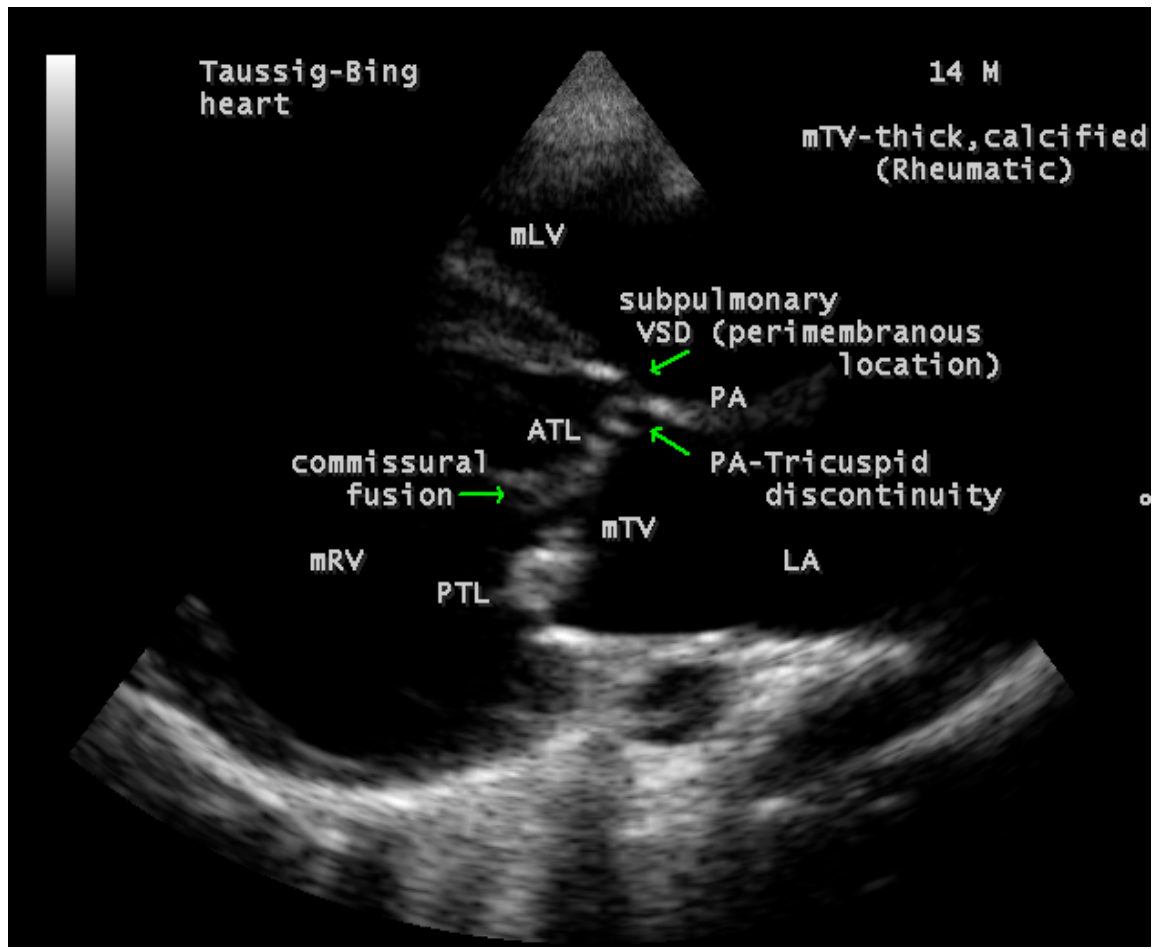

Figure 10. Subcostal view (long sweep) showing the thick, calcified morphologic tricuspid valve (mTV) with commissural fusion (right arrow) due to rheumatic etiology and a subpulmonary VSD (ventricular septal defect) (left upper arrow) with pulmonary-tricuspid discontinuity (left lower arrow) as a feature of DORV (double outlet right ventricle).

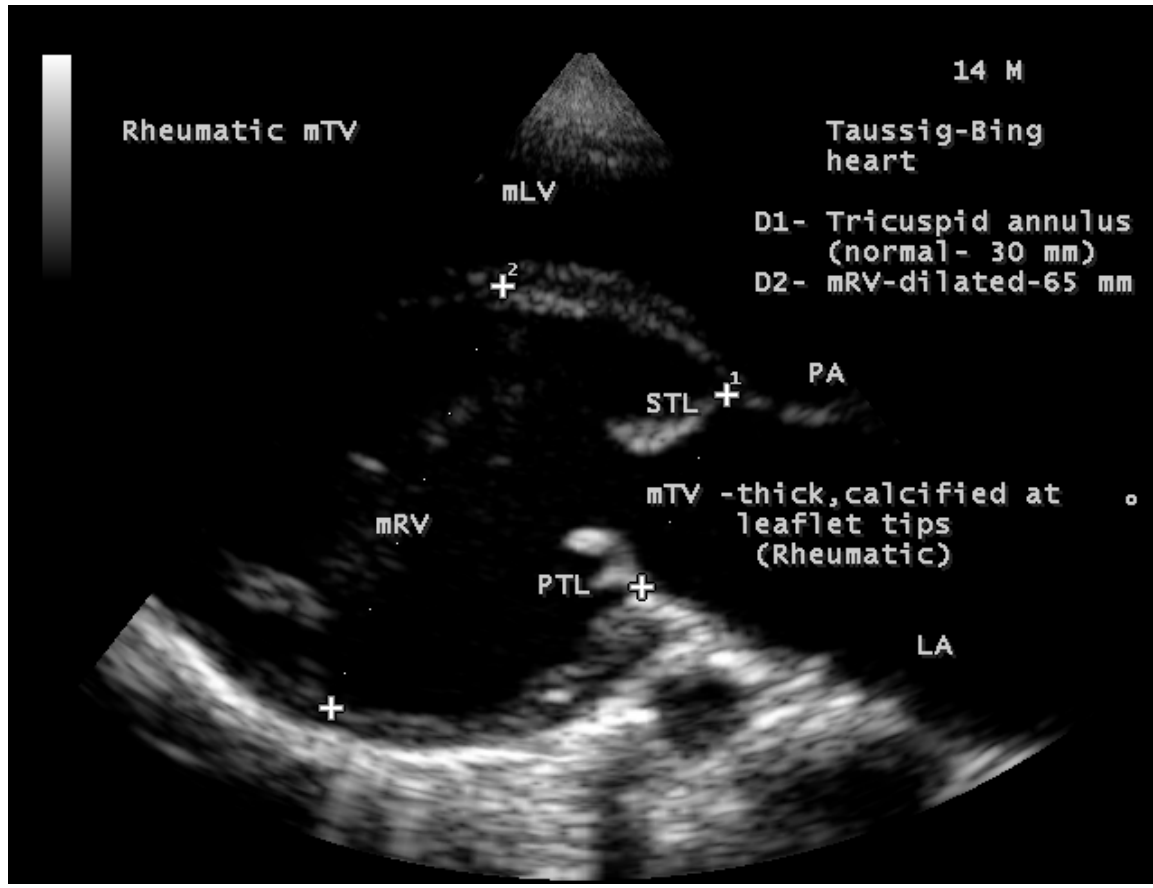

Figure 11. Subcostal view showing the calcification and thickening which is more prominent at leaflet tips due to rheumatic involvement, the normal tricuspid annulus (30 $\mathrm{mm}$ ) and a dilated morphologic right ventricle $(\mathrm{mRV})(65 \mathrm{~mm})$. 


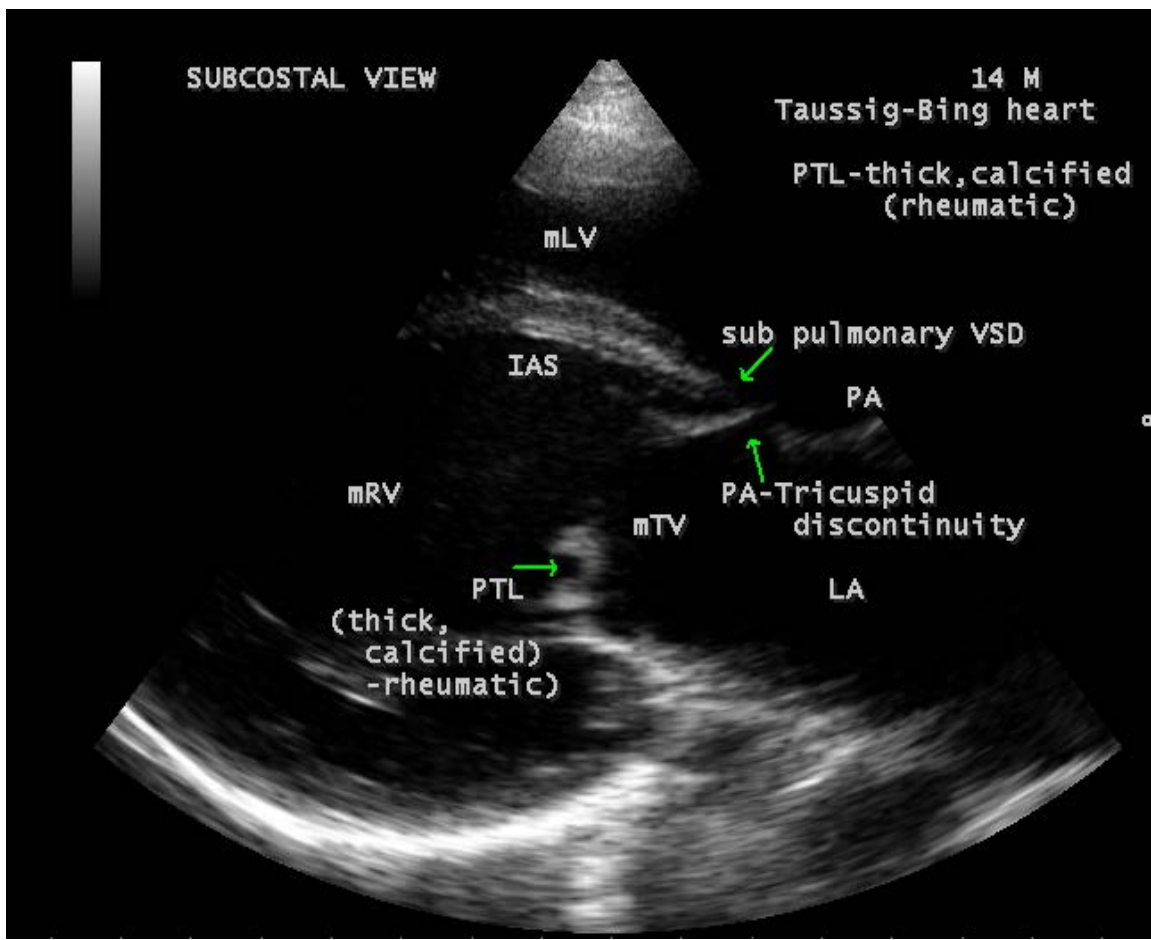

Figure 12. Subcostal view showing the marked rheumatic involvement of posterior leaflet of the morphologic tricuspid valve (mRV) (right arrow) and a subpulmonary VSD (ventricular septal defect) (left upper arrow) with pulmonary-tricuspid discontinuity (left lower arrow) as a feature of DORV (double outlet right ventricle).

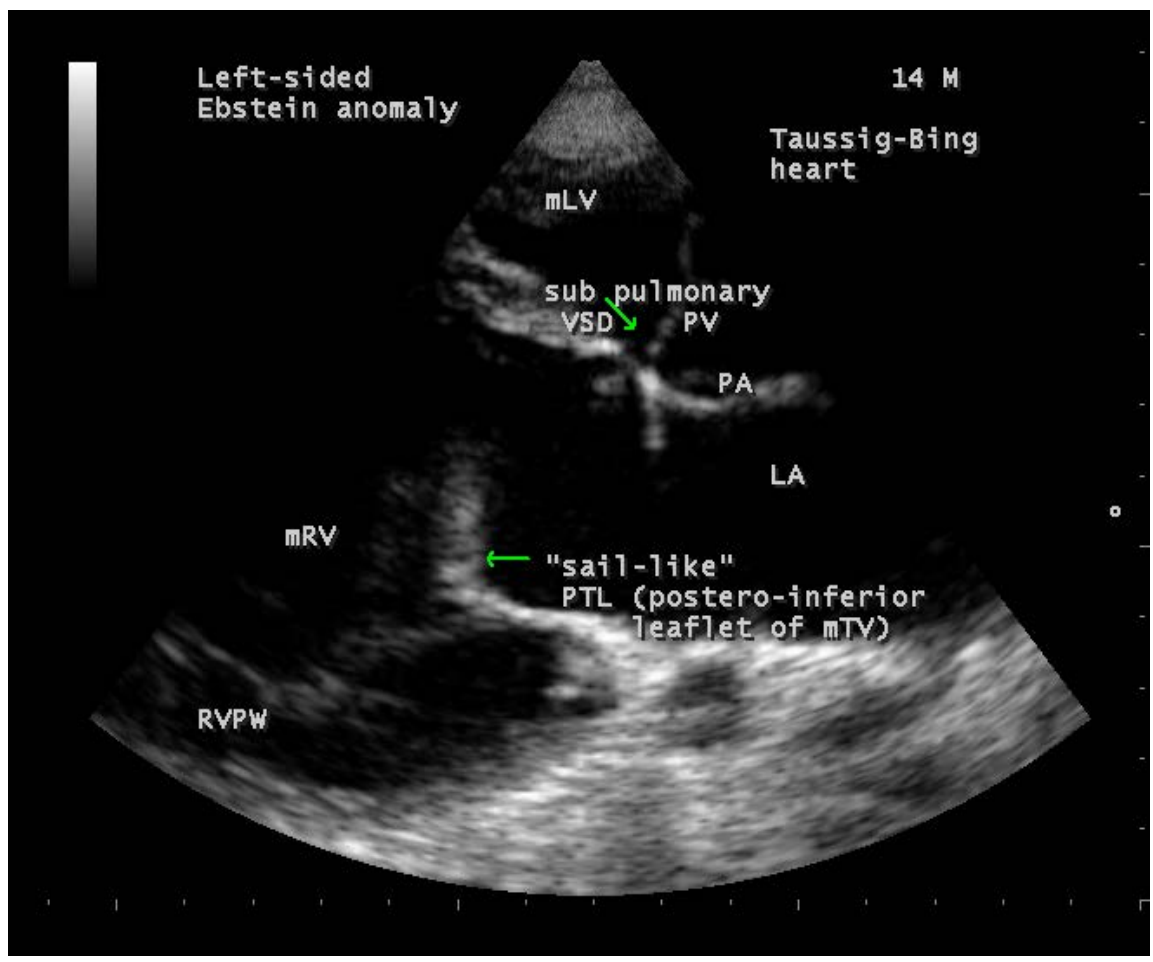

Figure 13. Subcostal view showing the "sail-like" deformity of posterior leaflet (PTL) of morphologic tricuspid valve (lower arrow) and a subpulmonary VSD (ventricular septal defect) (upper arrow). 


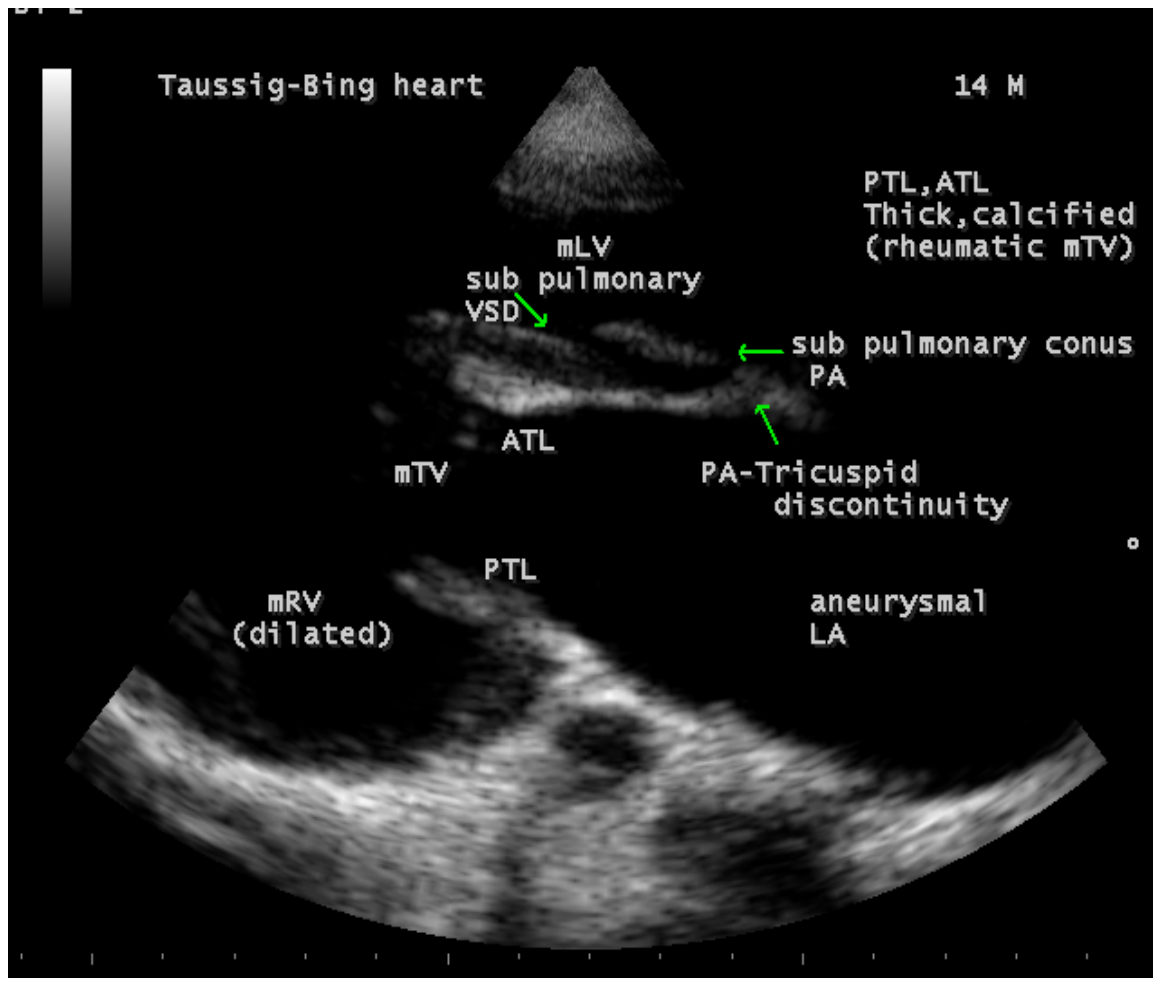

Figure 14. Subcostal view (long sweep) showing the subpulmonary VSD (ventricular septal defect) (right arrow) and a conal musculature (left upper arrow) with pulmonarytricuspid discontinuity (left lower arrow).

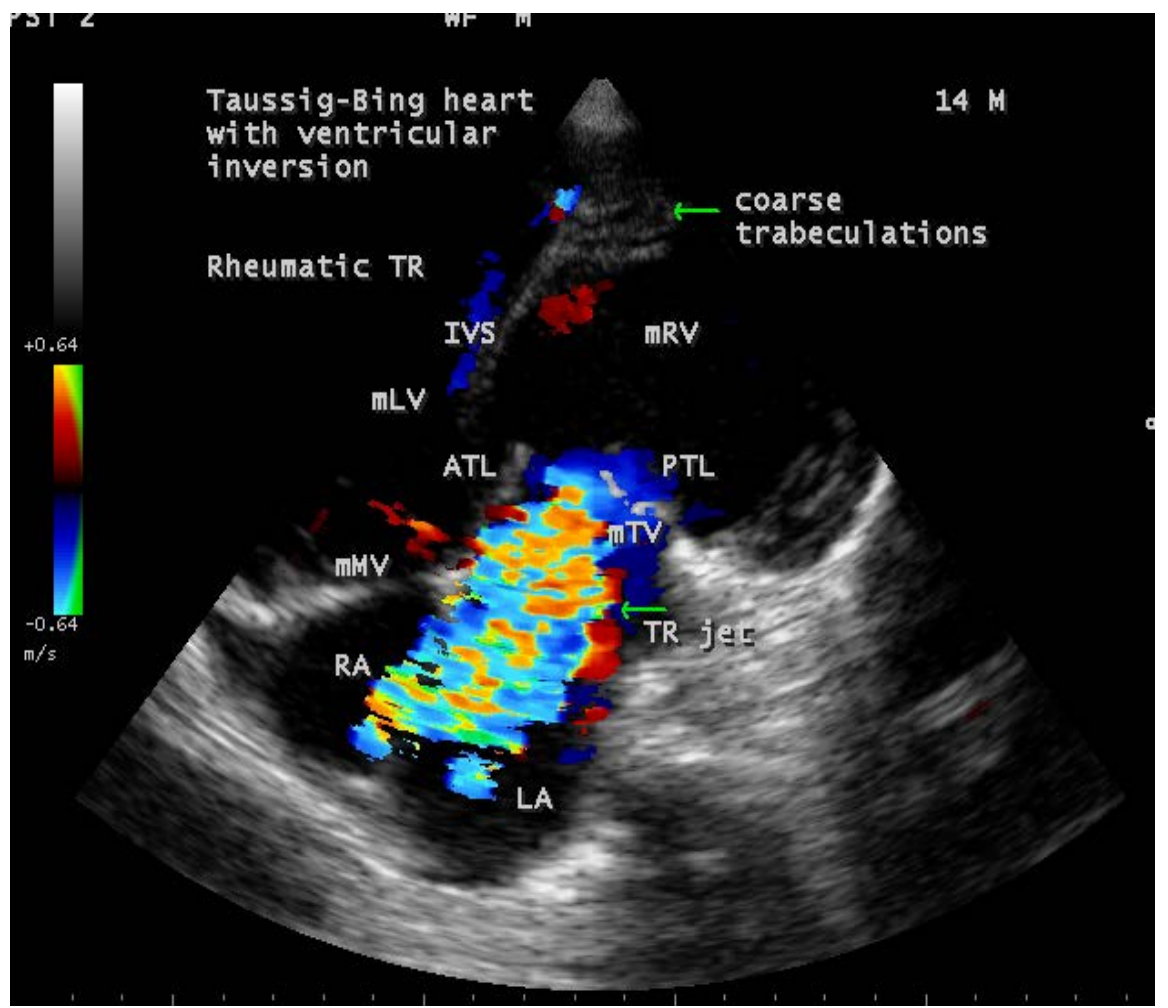

Figure 15. Apical view showing the severe tricuspid regurgitation (TR) (lower arrow) and coarse trabeculations of morphologic right ventricle (mRV) (upper arrow). 


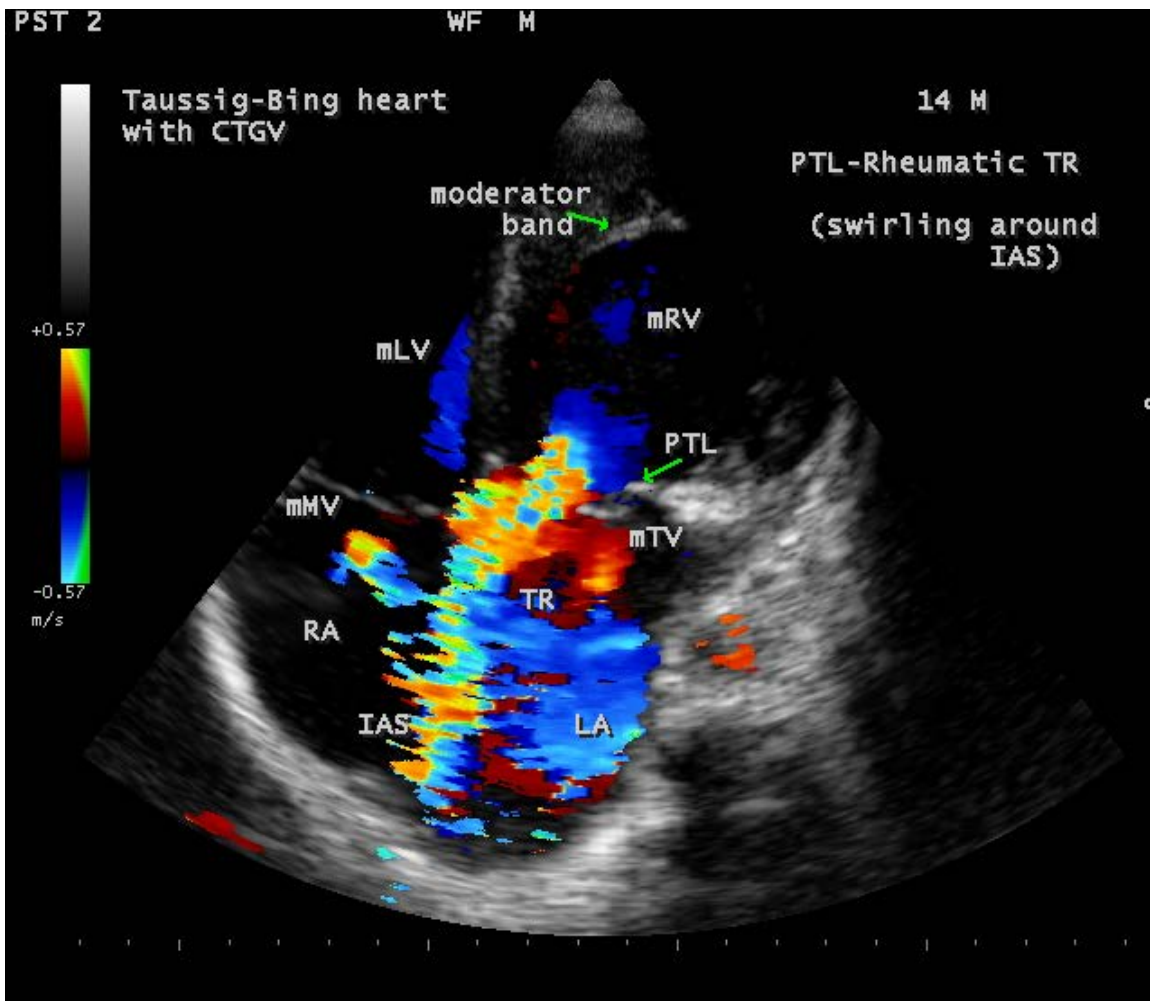

Figure 16. Apical view showing the tricuspid regurgitation jet swirling around the interatrial septum (IAS). PTL-posterior tricuspid leaflet (arrow).

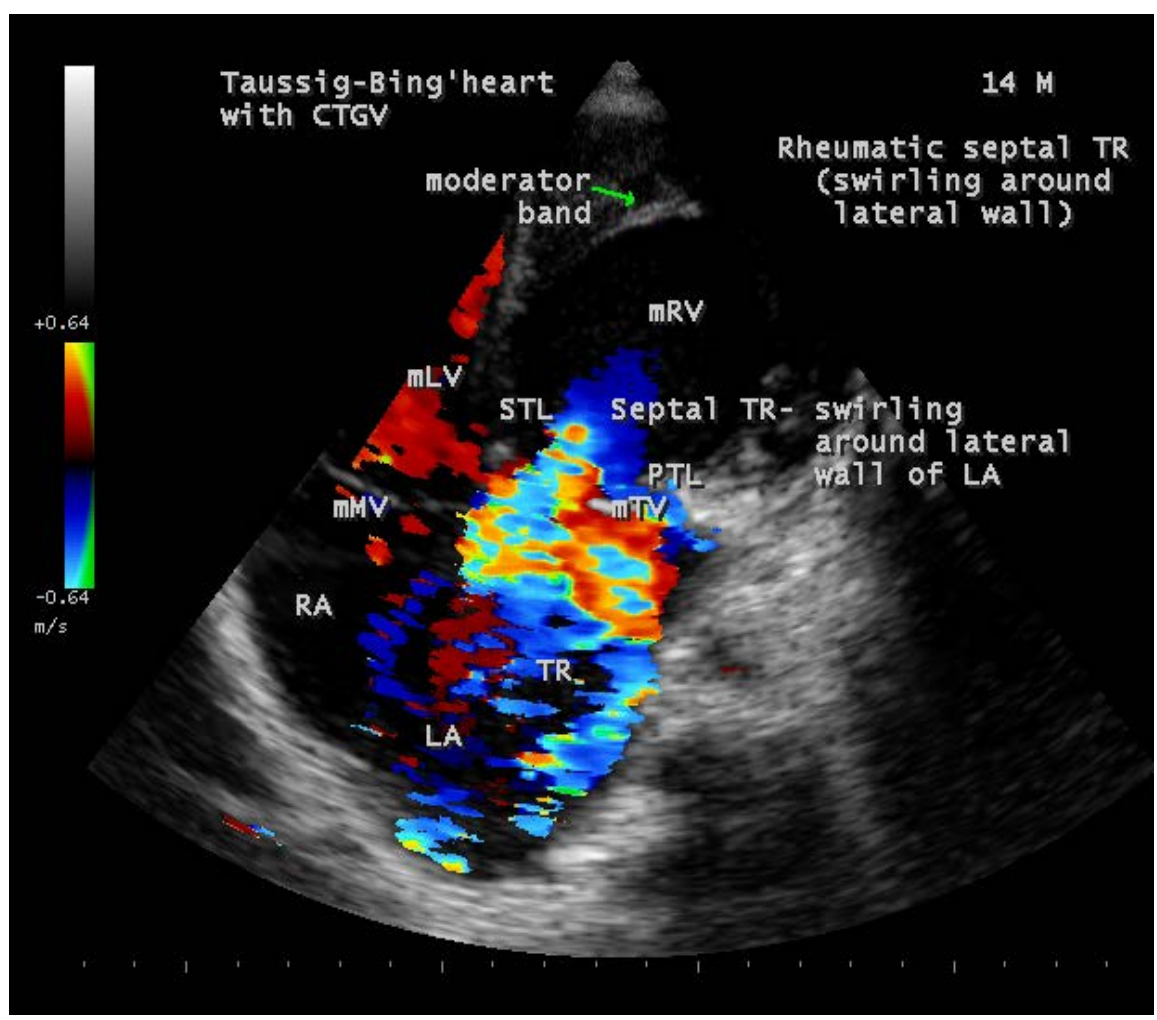

Figure 17. Apical view showing the tricuspid regurgitation jet swirling around the lateral wall of left atrium (LA). STL-septal tricuspid leaflet. 


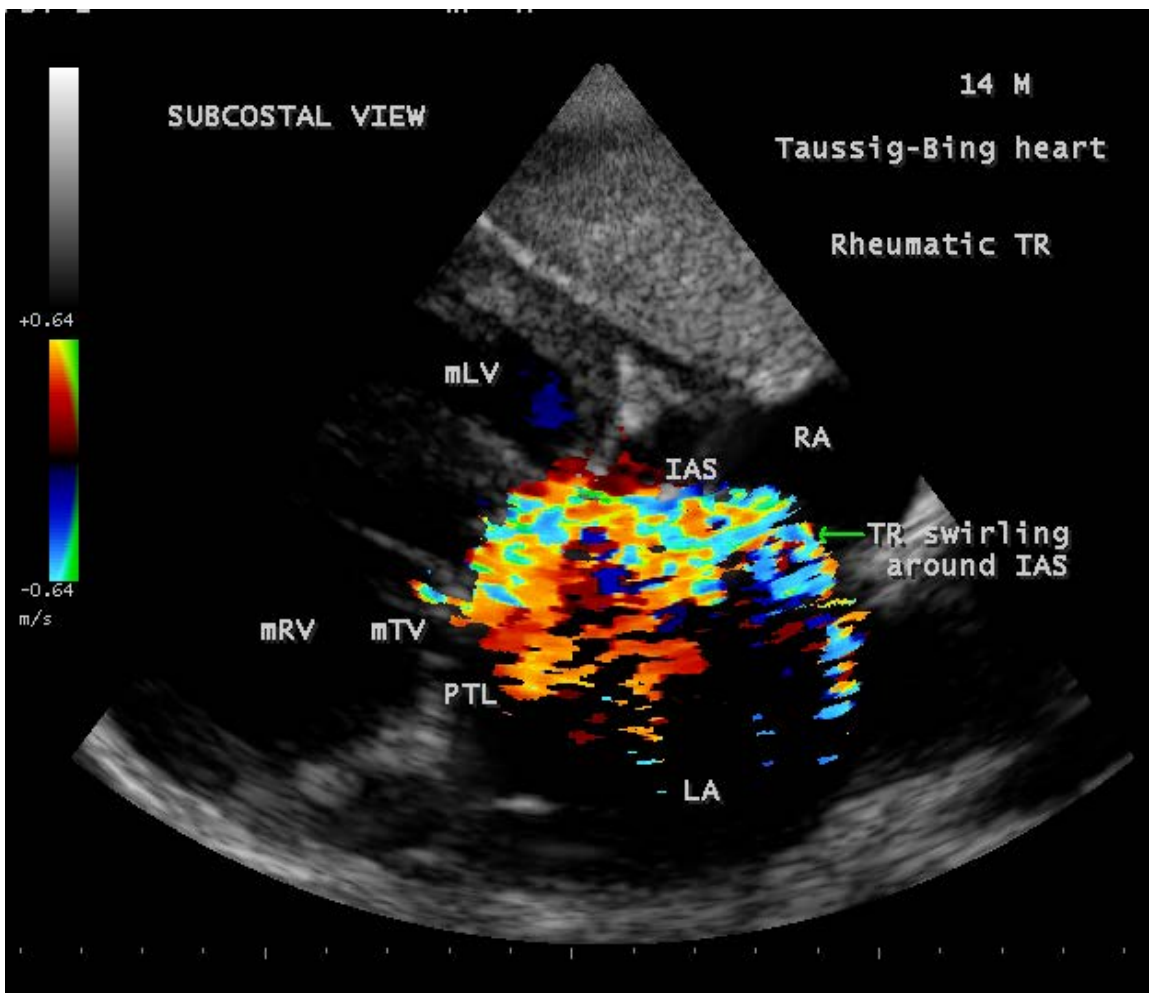

Figure 18. Subcostal view showing the severe tricuspid regurgitation originating from the posterior tricuspid leaflet (PTL) swirling around the interatrial septum (arrow).

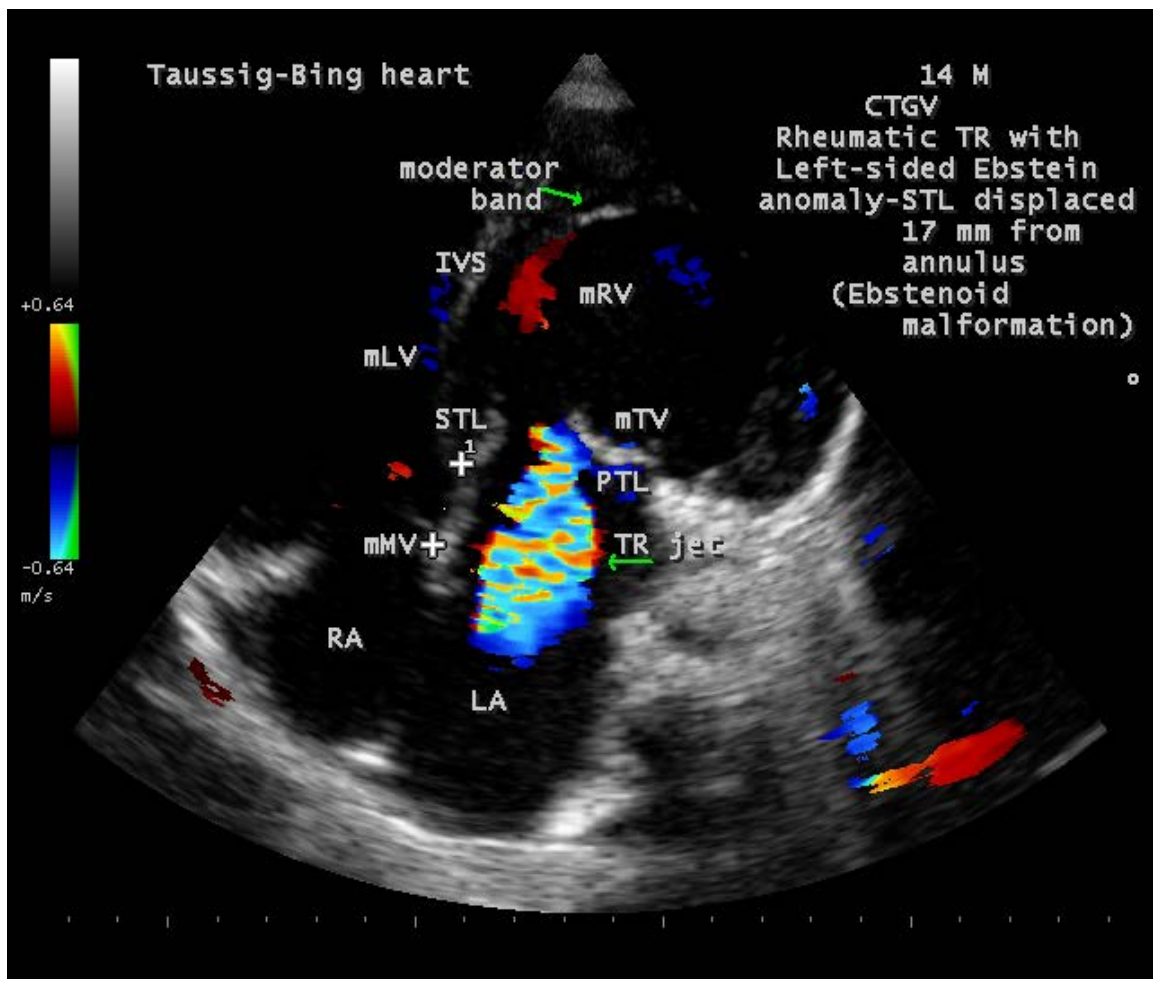

Figure 19. Apical view showing the decrease in regurgitant jet (arrow) due to aggressive medical treatment and left-sided Ebstenoid malformation due to adherence of septum (IVS) to STL. 




Figure 20. Subcostal view showing the marked decrease in regurgitant jet (left arrow) due to aggressive medical treatment. PTL-posterior tricuspid leaflet (right arrow).

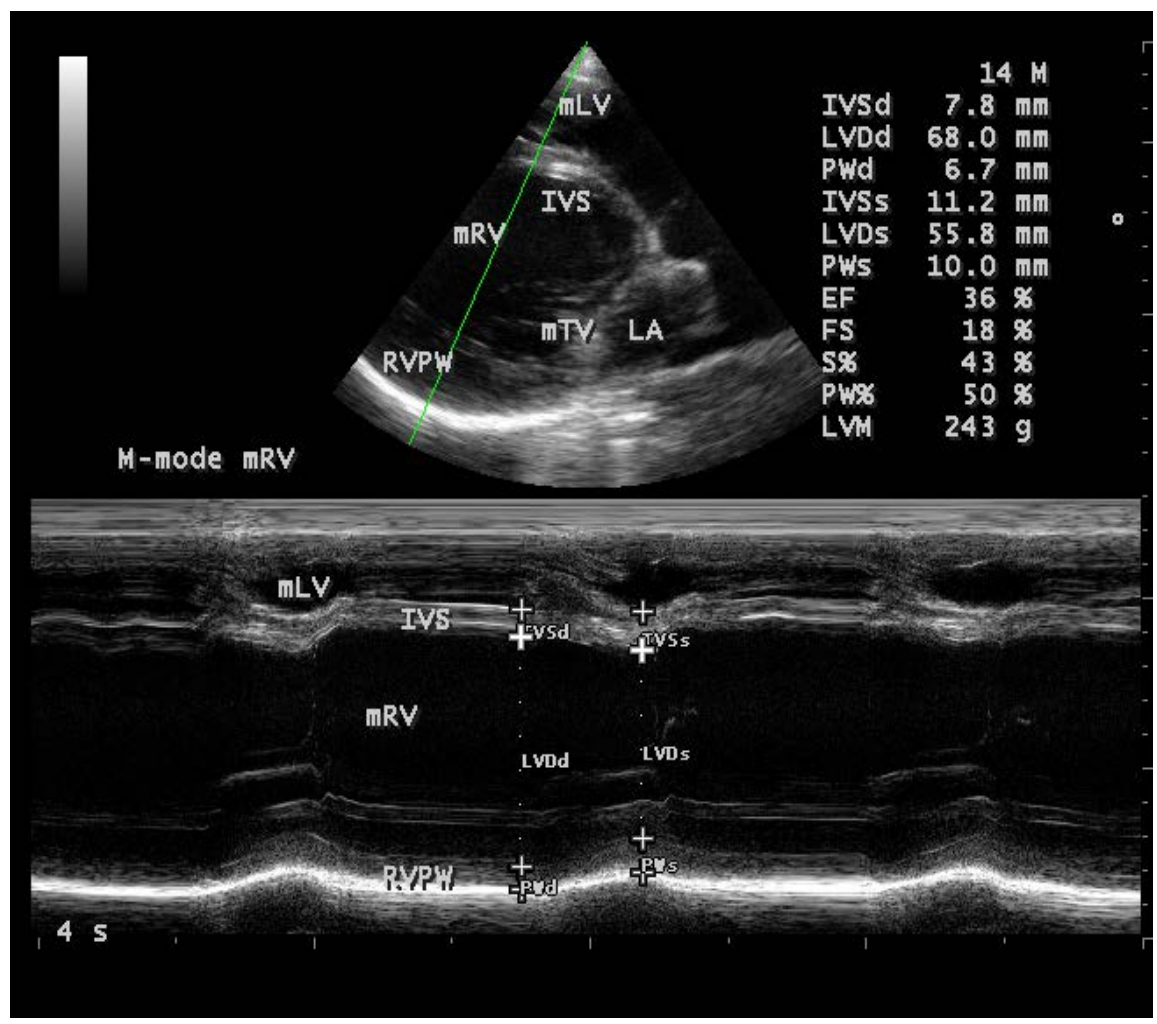

Figure 21. M-mode mRV study showing the severe dysfunction of morphologic right ventricle (mRV)-EF $36 \%$. 


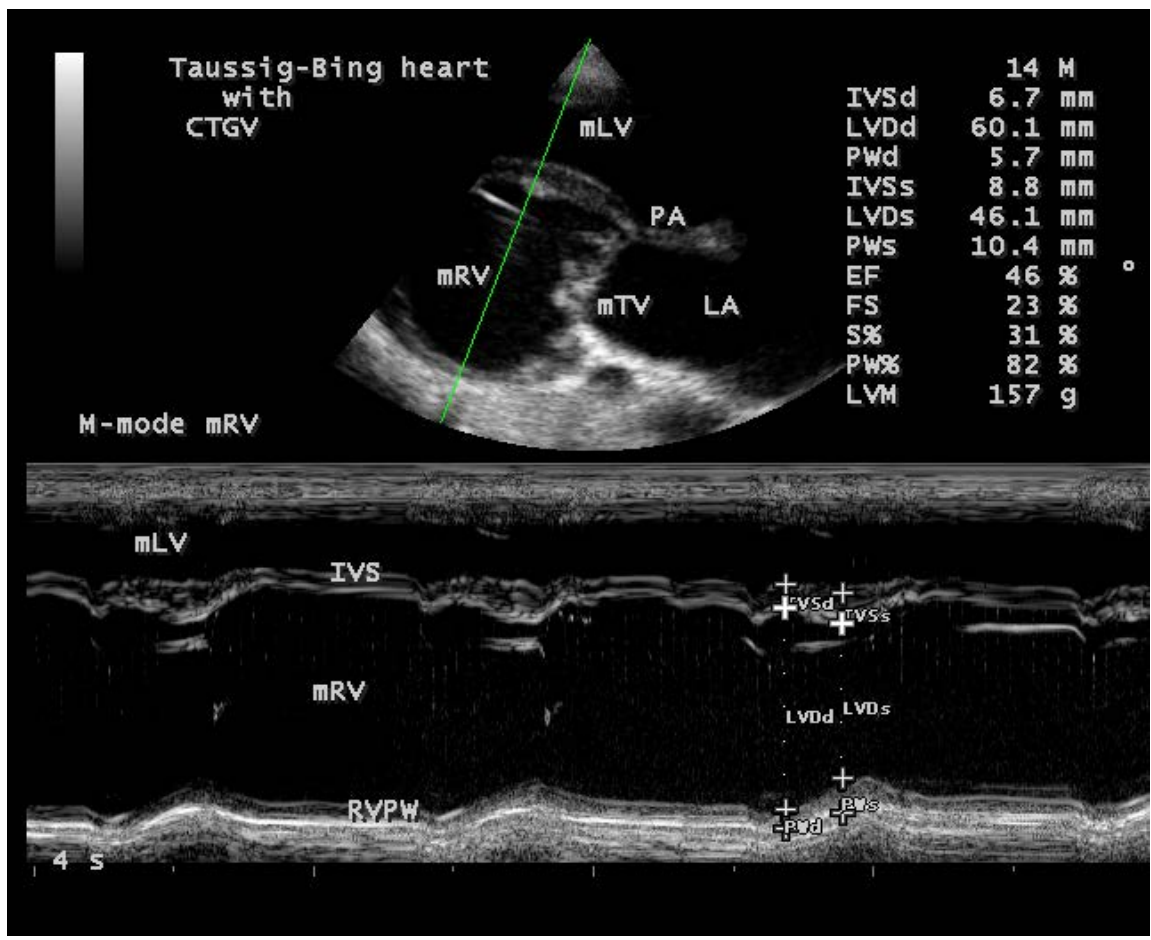

Figure 22. M-mode mRV study (green line) showing the improvement in RV function following aggressive medical treatment-EF $46 \%$.

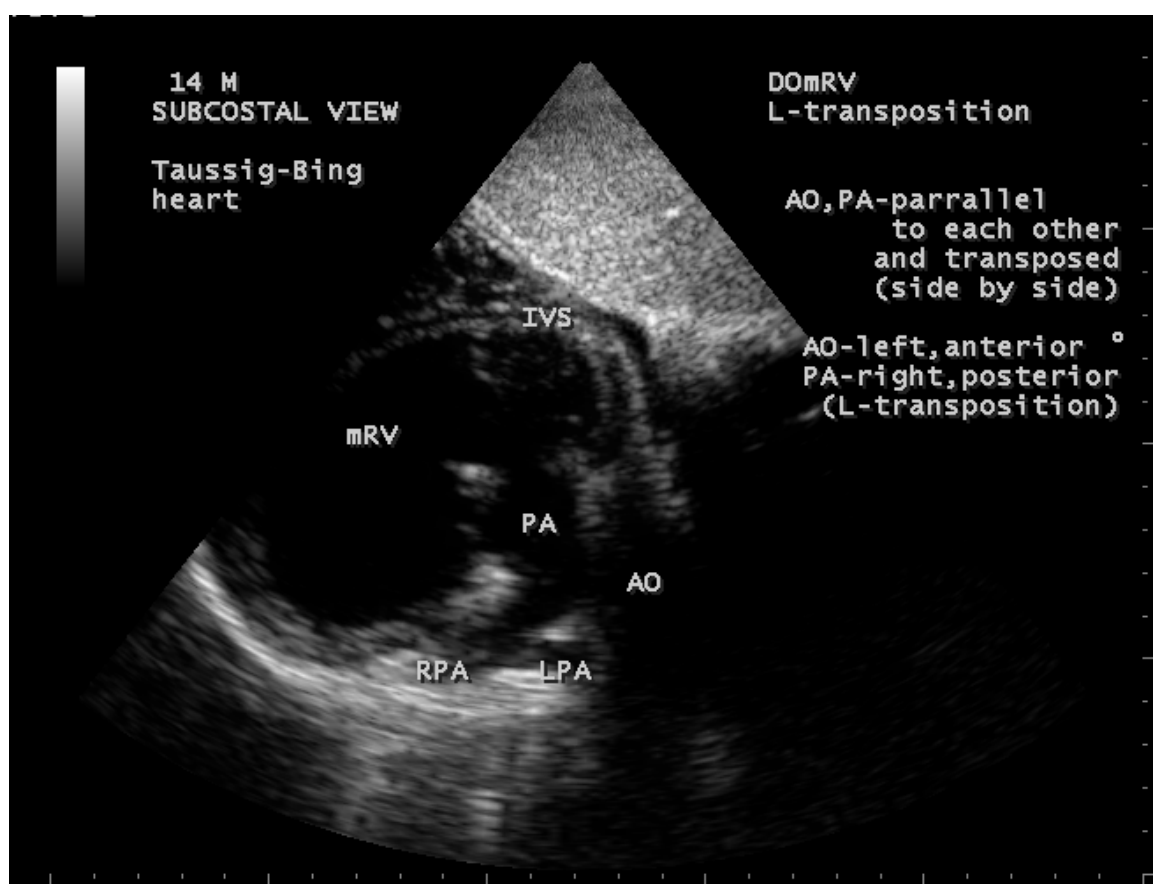

Figure 23. Subcostal view (short sweep) showing the primary origin of great vessels from the morphological right ventricle (mRV) and it is side-by-side (L-transposition).

is called as "corrected transposition" by Baron Rokitansky in 1875 and described as "Rokitansky's malformation" [13] in 1957 or L-transposition (Levo-transposition) or "ventricular inversion" and subsequently designated as "congenitally 


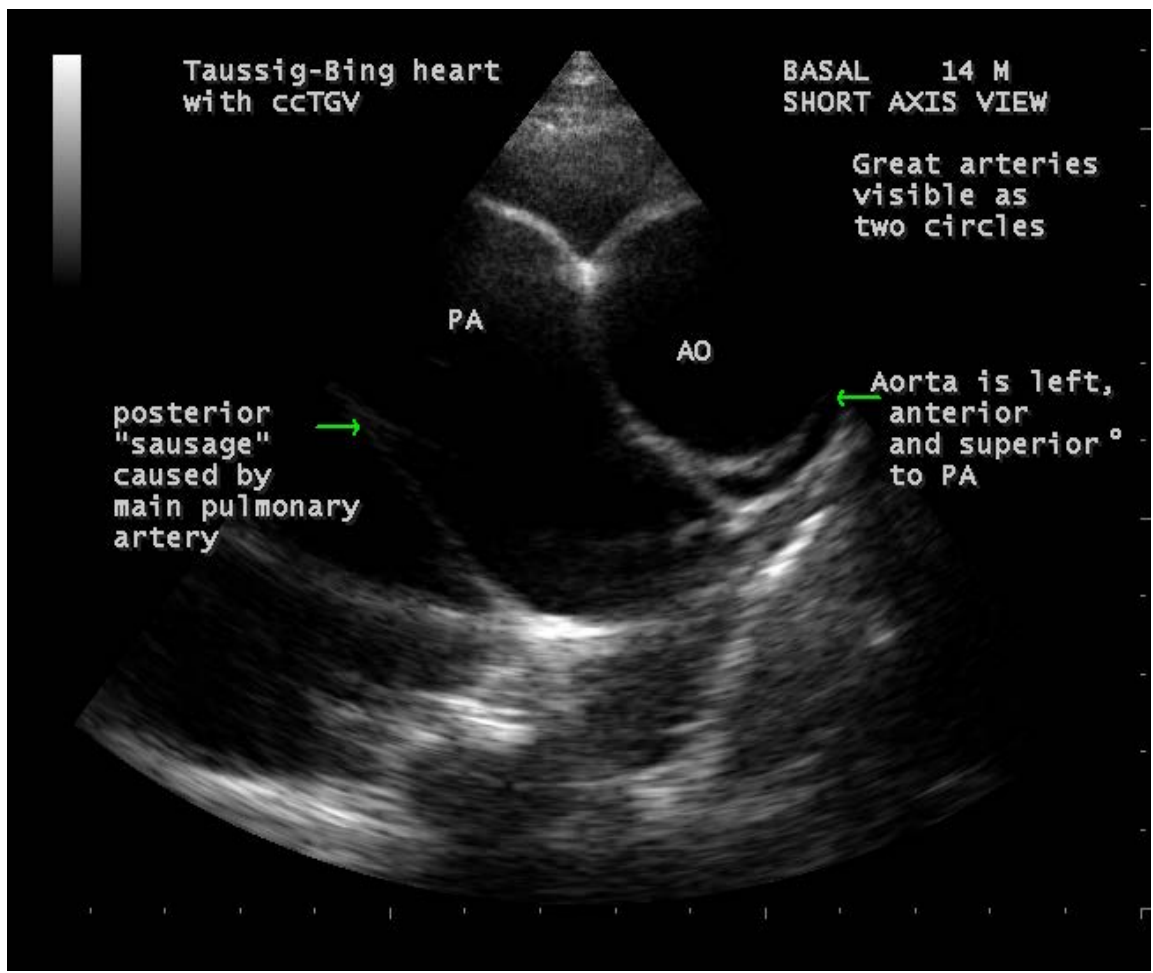

Figure 24. Basal short axis view showing the great arteries seen in circles. The posterior "sausage" caused by main pulmonary artery (right arrow) and the aorta (AO) is left, anterior and superior to pulmonary artery (PA) (left arrow) suggesting a side by side relationship.



Figure 25. Showing the dilated pulmonary trunk in Taussig-Bing heart and there is no obstructive lesions. MPA—dilated main pulmonary artery. 


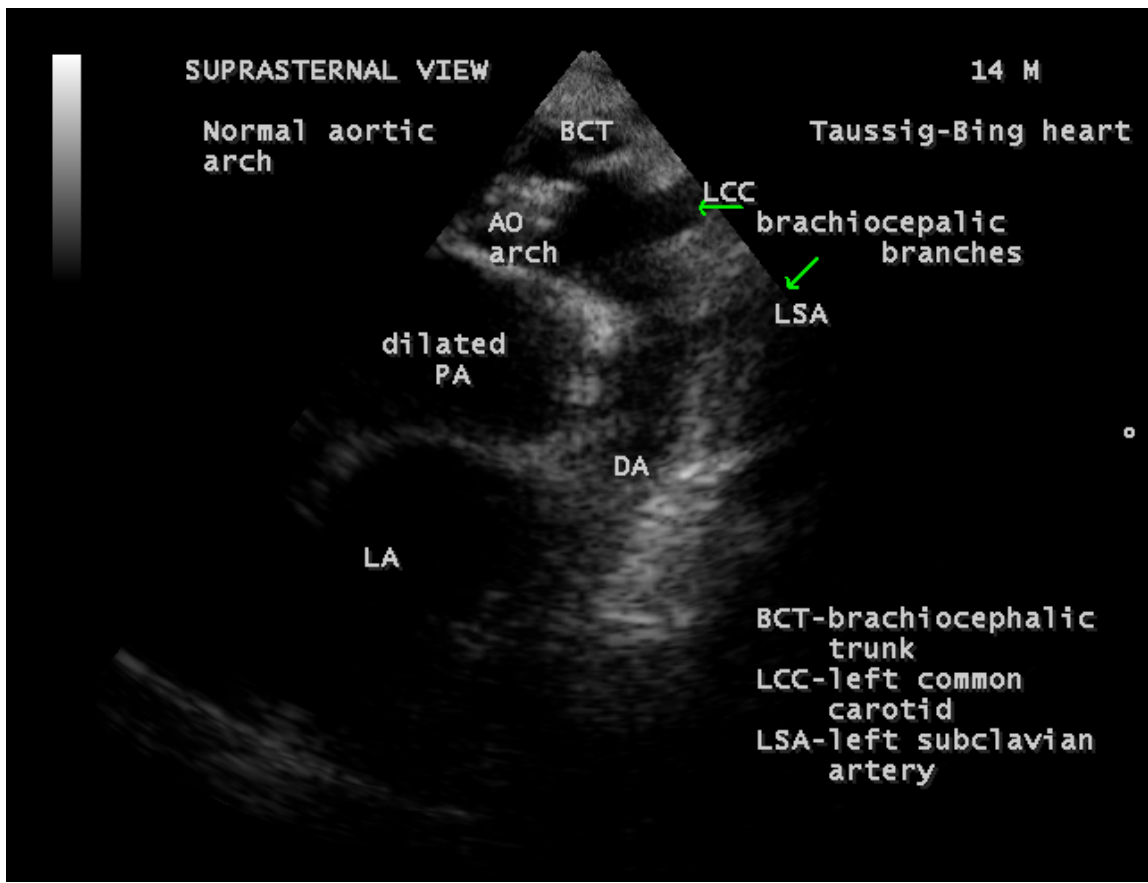

Figure 26. Suprasternal view showing the normal aortic arch and its branches (arrows).

corrected transposition" (ccTGV) by Schiebler since the correction was a gift of God, rather than the gift of the surgeon [14]. Abnormalities of the morphologic tricuspid valve (left AV valve) was seen in $90 \%$ of L-transposition in autopsy series and significant Ebstein-like malformation of left AV valve, i.e., the septal leaflet is displaced inferiorly towards the cardiac apex [15] as in Figure 7, $17 \mathrm{~mm}$ apical to the right-sided mitral valve (normally the distance between the tricuspid and mitral annulus is $<8 \mathrm{~mm} / \mathrm{m}^{2}$ (displacement index [16]), the left-sided Ebstein's anomaly [17] and it is less displacement than in the usual form of Ebstein's anomaly as in patients with concordant AV connections. The atrialization of the inlet of the morphologic right ventricle is also minimal and the "sail-like" deformity of postero-inferior leaflet of morphologic tricuspid valve is well marked in this case as in Figure 13 which is rarely seen in left-sided Ebstein's malformation. The unusual disposition of the conduction tissue that predisposes to spontaneous AV block [18] as in Figure 1, occurs in $1 / 10^{\text {th }}$ of infants born with this anomaly [19] [20] with an incidence of $2 \% / y e a r$ [21], as $45 \%$ will have developed third-degree AV block on 20-year follow up [22] and it reaches a prevalence of $10 \%$ to $15 \%$ by adolescence and $30 \%$ in adulthood [23]. In older patients, fibrotic invasion of proximal and distal bundle branches was involved in its pathogenesis.

The tricuspid valve tends to remain competent during the first decade of life, but progressively become incompetent during the $2^{\text {nd }}$ to $5^{\text {th }}$ decade in $20 \%$ to $50 \%$ of patients and it has been implicated as a cause of ventricular dysfunction due to volume overload. Since the morphologic right ventricle is in the systemic position, it is unable to generate the necessary forces to sustain the increasing 
work demand, such as exercise, similar to normal systemic left ventricle [24] due to the loss of special twisting motion during systole and early diastole [25] as it lacks the helical myocyte arrangement seen in left ventricle. The RV muscle mass increase significantly since it is subjected to systemic pressure, leading to right ventricular hypertrophy (RVH) as in ECG shown in Figure 1.

The VSD is neither membranous nor conal septal defect and it is due to its malalignment of well developed parietal conal free walls, the parietal and septal bands, which may separate or dissociate widely in Taussig-Bing malformation. In L-TGA, the VSDs occur in $60 \%-80 \%$ of cases, usually perimembranous, located below the pulmonary valve, extends posteriorly and inferiorly towards the crux of the heart and opening into the inlet of the morphologic left ventricle as in Figure 6. Endocardial cushions in the outflow tract are responsible for the formation of semilunar valves and the development of conal septum (the portion of ventricular septum between the distal ventricular outflow tracts). During this process, changes in position of anterior portion of the muscular interventricular septum and differential conus absorption leads to malposition of great artery relations. In S.L.L. type of ccTGV [26] (S-situs solitus of the viscera and atria, L-loop ventricle, L-transposition of great arteries), deviation in the normal development of interventricular septum as the ventral limb of the left interventricular sulcus on the primary heart tube gives rise to a left-sided crista supraventricularis, which, determines, in part, the right ventricular morphology of the left-sided ventricle. The dorsal limb spirals towards the atrioventricular canal, giving rise to a malpositioned interventricular septum, and displaces the embryologic right ventricle to the left. The course of outlet septum establishes the alignment of VSD with great arteries. If the outflow tract is straight and parallel to the trabecular septum, the VSD becomes subpulmonary and the extreme leftward rotation of the aorta resulting the great arteries nearly in a side-by-side relationship, with the aorta to the left.

The molecular and biological forces that dictate the abnormal cardiac looping in humans are not clear. Cytogenetic analysis identified the discrete chromosomal lesions in the morphogenesis of the heart and appears to be associated with subtypes of DORV. Type 1 DORV (with subaortic VSD) is associated with chromosome 22q11 deletion, the type II (with subpulmonary VSD (supracristal) -Taussig Bing type) with trisomy 13 or 18 . The transcription factors are postulated to influence the development of right ventricle and great arteries [27]. Type 1 DORV might reflect the abnormalities of neural crest cells necessary for the normal outflow tract development and the $T G F_{\beta}$ superfamily genes (activin type IIB receptor, noggin, $\left.T G F_{\beta 2}\right)$, Sox4 [28], NF1, RAR genes, Endothelin converting enzyme genes ( $E C E-1, E C E-2)$ and HAND1 gene also play a role. Mutations of GATA 4 gene has a potential for the development of type II DORV. Genes determining the body plans such as Pitx 2, CFC 1, Cx43 (left-right axis determination), Hox 1.5 (rostral-caudal specification) and jefty 1, inversin (abnormalities of situs and looping) for type 111 DORV (with doubly-committed 
VSD) and mutations in several other genes had been implicated in few cases of human DORV pertinent to animal models [29] [30]. Recently, it is noted that there is a relationship between primary ciliary dyskinesis (PCD) and ccTGV [31]. The association between cilia and cardiogenesis was made in a baby chick and Willaredt et al. [32] found a link between Sonic hedgehog signaling at the primary cilium and the role of bone morphogenic protein in the cardiogenesis of endocardial cushions.

Animal studies also implicate diverse teratogens, the commonly used drugs (ephedrine, theophylline, sodium valproate, retinoic acid/vitamin A, tedral (combination of theophylline, ephedrine, phenobarbitone), other agents including bis-diamine, bromodeoxyuridine), copper citrate, environmental factors such as hair dye, air pollutants [33] and maternal diabetes are enhancing the susceptibility of DORV phenotypes.

\subsection{Echocardiographic Features}

Transthoracic echocardiography is the first line modality to assess the specific relations of the different segments of the heart and to determine the presence of any associated malformations. The anatomical designation is first assigned by demonstrating atrial position, ventricular and arterial loopings. The morphology of right ventricle is determined by the presence of coarse trabeculations, moderator band and the level of tricuspid valve, which is inferior (apical) to mitral valve, also give a clue to ventricular inversion as shown in Figure 7. The morphology of tricuspid valve is characterized by a long, elongated posterior leaflet and a short septal or anterior leaflet in comparison to mitral valve, in which the posterior leaflet is short and the anterior leaflet is long and elongated as in Figure 4. The morphologic TV (tricuspid valve) is a systemic AV valve and its septal leaflet is abnormally displaced inferiorly. This systemic AV valve (mTV) is anatomically abnormal, that predicts the occurrence of regurgitation and transthoracic echocardiography is the technique of choice to evaluate the etiology of TR (tricuspid regurgitation) and in most cases, it is so called "functional" (secondary TR (tricuspid regurgitation) due to dilatation of annulus (diastolic diameter $>40 \mathrm{~mm}$ or $21 \mathrm{~mm} / \mathrm{m}^{2}$ )) as a consequence of RV dilation secondary to pulmonary hypertension. In $15 \%$ to $20 \%$ of cases, the injury to tricuspid valve can be organic and generally of rheumatic in origin. The morphologic TV (mTV) is thickened and calcified as in Figure 7, more prominent at leaflet tips as in Figure 11 with commissural fusion as in Figure 10, the posterior tricuspid leaflet is predominantly affected as in Figure 12 and it is severely regurgitant as shown in Figures 15-18, the annulus diameter is $30 \mathrm{~mm}(<40 \mathrm{~mm})$ as in Figure 11.

The anatomic objective such as "double discordance", i.e., discordant connection at both atrioventricular and ventriculo-arterial junctions can be defined by echocardiography. The discordance between the atrium and ventricle as left atrium is connected to the morphologic Right ventricle (mRV) and the right 
atrium is connected to the morphologic left ventricle $(\mathrm{mLV})$ was shown in Figure 7.

The origin of great arteries in relation to the septum and its spatial relationships are best visualized in subcostal coronal views. Figure 23 shows the origin of both great arteries primarily from the morphologic RV (mRV), it is parallel to each other (normally cross each other) and the pulmonary trunk is identified by its bifurcation into right and left branches. The great arteries appear as double circles in basal short axis view as in Figure 24 with posterior "sausage" caused by the main pulmonary artery segment, transected tangentially and an anterior circle which is the aorta, positioned leftward, anterior and superior to the pulmonary artery [34] suggesting L-transposition. The subcostal coronal view also helps to determine the lack of fibrous continuity between the posterior semilunar valve (pulmonary) and the anterior tricuspid leaflet as in Figure 10 and Figure 12 and suggesting double-outlet right ventricle with a subpulmonary VSD (Taussig-Bing type). In about $50 \%$ of cases of Taussig-Bing anomaly, the congenital malformation of the aorta including coarctation, isthmic hypoplasia, interruption, patent ductus arteriosus and subaortic conus may occur [35] [36]. The aorta is identified by its brachiocephalic branches, but the aortic arch appears normal in this patient as shown in Figure 26.

\subsection{Management}

Systemic AV valve regurgitation is a potential risk factor for the development of dysfunction of the morphologic RV and early heart failure [37] and those patients without such complications (i.e., in the absence of hemodynamic lesions) appear to function well into late adulthood in ccTGV [38] [39]. Medical management with diuretics, afterload reduction with angiotensin converting enzyme inhibitors such as captopril and digoxin (inotropic) is adapted for the failing systemic right ventricle [40], depending on the severity of associated malformations [41]. The role of angiotensin receptor blocker with losartan was evaluated and found to have no improvement in exercise capacity and no reduction in neurohormonal levels in patients with systemic right ventricle [42]. Beta blockers did not improve outcome in a randomized trial included pediatric patients with systemic RV dysfunction [43] and must be used cautiously in ccTGV patients as they may precipitate AV block, but an improvement in systemic ventricular function occurred after carvedilol (a vasodilatory beta blocker) administration in a 80-year old woman with ccTGV [44], Aggressive medical treatment with afterload reduction is indicated for patients with ventricular enlargement and early symptoms. The benefits of prophylactic use of vasodilators is unproven to delay or prevent systemic ventricular dysfunction.

\subsection{Interventional Therapy}

In patients with widened QRS complex (QRS duration > 120 - $140 \mathrm{~ms}$, sometimes $>200 \mathrm{~ms}$ ) due to bundle branch blocks, the electromechanical dyssyn- 
chrony create insufficiency in ventricular ejection and restoration of electrical synchrony with transvenous permanent para-Hisian pacing (cardiac resynchronization therapy) reduces the QRS duration and improves the hemodynamics of the failing systemic right ventricle [45] [46], but it is technically challenging [47]

Complete heart block is also a common cause of death [48]. Early pacemaker placement is recommended in the setting of complete heart block if there is RV dysfunction, symptoms of bradycardia or heart failure and urgently done if it occurs during or after the surgical intervention when the bradycardia is intolerable. It can be technically challenging pertaining to the complex heart anatomy [49] such as modification in position of ventricular septum that induces a septal shift and failure of tricuspid valve coaptation [50] leading to worsening of systemic ventricular function and $\mathrm{AV}$ valve regurgitation.

\subsection{Surgical Therapy}

The evolution of surgical repair for the Taussig-Bing anomaly has progressed from atrial baffle procedures to arterial switch with VSD closure and intraventricular repair. The need for surgical interventions vary according to the associated defects and several options are available as:

1) Physiologic or conventional repair-which emphasizes the correcting of associated defects without addressing the discordant connections and leaves the morphologic RV to propel the systemic circulation. The tricuspid valve and morphologic RV function is the Achilles heel of the physiology of ccTGV [51] [52]. Timely performed systemic AV valve replacement may preserve ventricular function, improves long-term outcome [53] and should be done prior to significant RV dysfunction in symptomatic patients and a preoperative ejection fraction of $\geq 40 \%$. Systemic AV valve repair have had disappointing intermediate and late results [54].

2) Anatomical repair-In physiological correction, the morphological RV will likely to fail over long-term, there is an increasing trend towards anatomical correction by "switch procedures" introduced in 1987 by Ilbawi and colleagues with an aim to utilize the morphologic LV as a systemic pumping chamber and the mitral valve as the systemic valve [55]. The goal of anatomic correction is the rerouting of the pulmonary venous return to $\mathrm{mLV}$ (morphologic LV) and aorta, the systemic venous return to $\mathrm{mRV}$ (morphologic RV) and pulmonary artery that achieving a normal anatomical pattern of circulation., i.e., morphologic LV to aorta and morphologic RV to pulmonary artery.

It represents a group of procedures in which $\mathrm{AV}$ discordance is corrected by an inflow, baffling procedure at atrial level, called as atrial or venous switch (Mustard or Senning) and the ventriculo-arterial discordance is corrected by either an outflow procedure called as arterial or ventricular switch or by translocation of the aortic root (Jatane procedure) and collectively termed as "double-switch". The choice of procedures depending on the underlying anatomy of LVOT/or morphology of VSD [56]. A modification of atrial switch 
procedures to a hemi-Mustard technique can be performed to overcome the high early morbidity and mortality in more complex anatomy patients to decrease the surgical challenge [57].

The indication for anatomic repair for those with a "balanced" systemic and pulmonary blood flow without clinically significant cyanosis is still unclear. Current indication for "double switch" operation include patients who have developed symptoms attributed to tricuspid regurgitation or RV dysfunction or both [58]. The anatomic repair is currently the first choice for most surgeons in treating ccTGV [59], only meant for patients with a favourable anatomy [60] and it remains the best choice for TGA type of DORV [61]. Early prophylactic pulmonary banding [62] as a bridge to "double switch surgery" related to LV retraining in selected asymptomatic young infants with isolated ccTGA is a challenging practice to expand anatomic repair in those patients who suffer from persistent late LV failure due to LV retraining.

For patients with Taussig-Bing type of DORV, the "arterial switch" operation still appears to be the procedure of choice and can be performed in the neonatal period [63] and also in patients with all types of great artery anatomy without ventriculotomy. The arterial switch for Taussig-Bing heart was first reported in 1981 [64]. The issue of great artery anatomy was first addressed by Yacoub and Radley-Smith [65] and many surgeons have thought that the side-by-side great arteries are most suitable for intraventricular repair (Kawashima repair) [66] [67], which is also applicable to unusual coronary artery anatomy or a pulmonary valve that is not considered adequate to function as a systemic valve. The antero-posterior great arteries are most suitable for arterial switch with a closure of VSD. The distance between the tricuspid and pulmonary valve for an intraventricular tunnel [68] is more important than the great artery relations and in side-by-side great arteries, the conduit can pass posteriorly and allow unimpeded flow to the pulmonary valve, i.e., by tunneling the left ventricular flow posterior to the pulmonary valve. The operative mortality for arterial switch is $13 \%, 3 \%$ for intraventricular repair and late mortality for both series is $5 \%$ to $6 \%$.

3) Single-ventricle palliation-such as "Fontain circulation" (redirection of systemic (deoxygenated) blood into the pulmonary artery without traversing a ventricle) should be considered in more complex and unfavourable anatomy due to small RV, chordae straddling and remote VSD, however, it may affects the organs outside the heart leading to cirrhosis, protein loosing enteropathy and plastic bronchitis [69].

\subsection{Outcome}

In patients without tricuspid valve regurgitation, the survival rate at 20 years is > $90 \%$ and it is $<50 \%$ in regurgitant lesions. Unfortunately, the patients are often referred late for surgery when a progressive RV dysfunction is already initiated, however, if the surgery is performed when the RV ejection fraction is $>40 \%$, the 
patients do reasonably well. In addition, a number of reports of ccTGA in adults come to medical attention for either cardiac or non cardiac reasons in $6^{\text {th }}$ to $8^{\text {th }}$ decade, indeed, the right ventricle can function as a systemic ventricle for many years [70].

\subsection{Case Analysis}

The 14-year old boy was presented with features of "double discordance" (Figure 7) with primary origin of L-transposed great arteries from the left-sided morphologic right ventricle (Figure 23) and a pulmonary-tricuspid discontinuity with well developed pulmonary conus (Figure 14) and a subpulmonary VSD (Figure 10), suggesting a "Taussig-Bing heart" with L-transposition. The visceral situs was normal (Figure 5) and there is a marked RV dilatation (Figure 11) with severe tricuspid regurgitation (Figures 15-18) due to rheumatic etiology (Figures 10-12) and so it is designated as "Rheumatic Taussig-Bing heart".

The septal malalignment in situ solitus alters the cardiac hemodynamics and conduction pathways, leading to increased risk of complications. The atrial and ventricular septa are malaligned and the AV node cannot penetrate the ventricular mass, indeed, a secondary node penetrates the anterior septum, predisposing to high grade atrioventricular block [71] (Figure 1) with a tolerable heart rate $(50 \mathrm{bpm})$ due to congenital etiology. The septal malalignment in situs solitus also leads to a high prevalence of Ebstein-like anomalies and 50\% of ccTGV patients had abnormal tricuspid valve. The left-sided Ebstenoid-like malformation of mTV as in Figure 7 (apical four chamber view) is due to septal malalignment, mimicking as apical displacement of septal tricuspid leaflet which is normally attached to annulus as in Figure 8 and Figure 9 shown in subcostal views with a subpulmonary VSD as in Figure 10 as the result of this septal malalignment.

On aggressive medical management with antifailure measures and penicillin prophylaxis, the severe tricuspid regurgitation decreases as shown in Figures 19 and Figure 20. It is a primary tricuspid regurgitation due to rheumatic involvement of mTV and the tricuspid annulus is not dilated $(<40 \mathrm{~mm})$ as in Figure 11. The mRV function improves from the severe dysfunction (Figure 21-EF 36\%) to a moderate degree (Figure $22-\mathrm{EF} 46 \%$ ).

The boy remains acyanotic with an improvement in hemodynamic status, the medical measures are continued with lifelong penicillin prophylaxis and advised periodic echocardiographic evaluation to assess the ventricular function. Since the left-sided morphologic RV is a systemic pumping chamber, it is hypertrophied (Figure 1) and may deteriorate in function on long-term follow-up. Since the both ventricles are adequate without any outflow tract obstructions (Figure 25, Figure 26) and the great arteries are in side-by-side, the Kawashima intraventricular repair is the preferred surgical option with tricuspid valve replacement in this boy. The pacemaker implantation is necessary when the heart rate becomes intolerable especially during surgical procedures. 


\section{Conclusion}

Taussig-Bing heart is one of the variants of double-outlet right ventricle (DORV) [72] and it constitues $<10 \%$ of cases of DORV. It is considered as a spectrum of anomalies, unified by a juxta-pulmonary VSD with malalignment of infundibular septum as double outlet right ventricle (Type II DORV-Taussig-Bing type) at one end and a discordant ventriculo-arterial connection at the other end. The options of surgical correction are determined by internal morphology of the lesions. The arterial switch operation appears to be preferred [73] and in selected cases, excellent early and intermediate survival had been reported with Kawashima intraventricular repair [74] recently. Vitamin E administration results a notable reduction in the severity of cardiac malformations in animal models, especially in diabetic pregnant mice due to its antioxidant effect [75].

\section{References}

[1] Walters III, H.L., Mavroudis, C., Tchervenkov, C.I., Jacobs, J.P., Lacour-Gayet, F., et al. (2000) Congenital Heart Surgery Nomenclature and Database Project: Double Outlet Right Ventricle. Annals of Thoracic Surgery, 69, S249-S263.

https://doi.org/10.1016/S0003-4975(99)01247-3

[2] Taussig, H.B. and Bing, R.J. (1949) Complete Transposition of Aorta and Levoposition of Pulmonary Artery. American Heart Journal, 37, 551. https://doi.org/10.1016/0002-8703(49)91133-3

[3] Van Praagh, R. (1968) What Is the Taussig-Bing Malformation? Circulation, 38, 445-449. https://doi.org/10.1161/01.CIR.38.3.445

[4] Stellin, G., Zuberbuhler, J.R., Erson, R.H. and Siewers, R.D. (1987) The Surgical Anatomy of the Taussig-Bing Malformation. Journal of Thoracic and Cardiovascular Surgery, 93, 560-569.

[5] Wilcox, B.R., Cook, A.C. and Erson, R.H. (2006) Surgical Anatomy of the Heart. $3^{\text {rd }}$ Edition, Cambridge University Press, UK.

[6] Van Praagh, R. and Van Praagh, S. (1966) Isolated Ventricular Inversion: A Consideration of Morphogenesis, Definition and Diagnosis of Nontransposed and Transposed Great Arteries. American Journal of Cardiology, 17, 395. https://doi.org/10.1016/0002-9149(66)90222-0

[7] Van Praagh, R. and Van Praagh, S. (1967) Anatomically Corrected Transposition of Great Arteries, British Heart Journal, 29, 112. https://doi.org/10.1136/hrt.29.1.112

[8] Bing, R.J. (1988) The Johns Hopkins: The Blalock-Taussig Era. Perspectives in Biology and Medicine, 32, 85-90. https://doi.org/10.1353/pbm.1988.0000

[9] Lev, M. and Volk, B.W. (1950) The Pathologic Anatomy of The Taussig-Bing Heart: Riding Pulmonary Artery. Report of a Case. Bulletin of the International Association of Medical Museums, 31, 54-64.

[10] Lev, M., Rimoldi, H.J., Eckner, F.A., Melhuish, B.P., Meng, L. and Paul, M.H. (1966) The Taussig-Bing Heart. Qualitative and Quantitative Anatomy. Archives of Pathology, 81, 24-35.

[11] Sridaromont, S., Ritter, D.G., Feldt, R.H., et al. (1978) Double-Oulet Right Ventricle: Anatomic and Angiocardiographic Correlations. Mayo Clinic Proceedings, 53, 555-577.

[12] Goor, D.A. and Edwards, J.E. (1973) The Spectrum of Transposition of the Great 
Arteries: With Specific Reference to Developmental Anatomy of the Conus. Circulation, 48, 406-415. https://doi.org/10.1161/01.CIR.48.2.406

[13] Anderson, R.C., Lillehei, C.W. and Lester, R.G. (1957) Corrected Transposition of Great Vessels of the Heart: A Review of 17 Cases. Pediatrics, 20, 626.

[14] Schiebler, G.I., Edwards, J.E., Burchell, H.B., et al. (1961) Congenital Corrected Transposition of Great Vessels. Pediatrics, 27, 851.

[15] Anderson, K.R., Danielson, G.K., McGoon, D.C. and Lie, J.T. (1978) Ebstein's Anomaly of the Left-Sided Tricuspid Valve: Pathological Anatomy of the Valvular Malformation. Circulation, 58, 187-191.

[16] Shiina, A., Seward, J.B., Edwards, W.D., et al. (1984) Two-Dimensional Echocardiographic Spectrun of Ebstein's Anomaly: Detailed Anatomic Assessment. Journal of American College of Cardiology, 3, 356-370. https://doi.org/10.1016/S0735-1097(84)80020-0

[17] Prieto, L.R., Hordof, A.J., Secic, M., Rosenbaum, M.S. and Gersony, W.M. (1998) Progressive Tricuspid Valve Disease in Patients with Congenitally Corrected Transposition of the Great Arteries. Circulation, 98, 997-1005.

[18] Kayrak, M., Kaya, Z., Gul, E.E., et al. (2010) Congenitally Corrected Transposition of Great Arteries with Severe Rhythm Disturbances. Indian Pacing and Electrophysiology Journal, 10, 179-183.

[19] Cardell, L.S. (1956) Corrected Transposition of the Great Vessels. British Heart Journal, 18, 186. https://doi.org/10.1136/hrt.18.2.186

[20] Friedberg, D.Z. and Nadas, A.S. (1970) Clinical Profile of Patients with Congenitally Corrected Transposition of the Great Arteries. A Study of 16 Cases. New England Journal of Medicine, 282, 1053. https://doi.org/10.1056/NEJM197005072821901

[21] Jalalian, R., Masoumi, S. and Ghaemian, A. (2011) Diagnosis of a Congenitally Corrected Transposition of the Great Arteries in a 50-Year Old Muiltiparous Woman. Cardiovascular Journal of Africa, 22, 203-204. https://doi.org/10.5830/CVJA-2010-053

[22] Nierras, P.C.M., Maranian, A.P., Wen, M.-S. and Chou, C.-C. (2016) Radiofrequency Catheter Ablation of Incessant Orthodromic Atrioventricular Reentrant Tachycardia in a Child with Congenitally Corrected Transposition of the Great Arteries and Atrial Septal Defect. International Journal of Cardiology, 212, 277-279. https://doi.org/10.1016/j.ijcard.2016.03.170

[23] Huhta, J.C., Maloney, J.D., Ritter, D.G., Ilstrup, D.M. and Feldt, R.H. (1983) Complete Atrioventricular Block in Patients with Atrioventricular Discordance. Circulation, 183, 1374. https://doi.org/10.1161/01.CIR.67.6.1374

[24] Peterson, R.J., Franch, R.H., Fajman, W.A. and Jones, R.H. (1988) Comparison of Cardiac Function in Surgically Corrected and Congenitally Corrected Transposition of the Great Arteries. Journal of the Thoracic and Cardiovascular Surgery, 96, 227.

[25] Shapiro, E.P. and Rademakers, F.E. (1997) Importance of Oblique Fiber Orientation for Left Ventricular Wall Deformation. Technology and Health Care, 5, 21-28.

[26] Van Pragg, R., Papagiannis, J., Grunenfelder, J., Bartram, U. and Martanovic, P. (1998) Pathologic Anatomy of Corrected Transposition of the Great Arteries Medical and Surgical Implications. American Heart Journal, 135, Part I, 772-785.

[27] Srivastava, D. (2006) Making or Breaking the Heart from Lineage Determination to Morphogenesis. Cell, 126, 1037-1048.

[28] Schilham, M.W., Oosterwegel, M.A., Moerer, P., Ya, J., DeBoer, P.A., VanDeWetering, M., Verbeek, S., Lamers, W.H., Kruisbeek, A.M., Cumano, A. and Clevers, 
H. (1996) Defects in Cardiac Outflow Tract Formation and Pro-B-Lymphocytes Expansion in Mice Lacking Sox-4. Nature, 380, 711-714. https://doi.org/10.1038/380711a0

[29] Huang, G.Y., Wessels, A., Smith, B.R., Linask, K.K., Ewart, J.L. and Lo, C.W. (1998) Alteration in Connexin 43 Gap Junction Gene Dosage Impairs Conotruncal Heart Development. Developmental Biology, 198, 32-44. https://doi.org/10.1006/dbio.1998.8891

[30] Kathiriya, I.S. and Srivastava, D. (2000) Left-Right Asymmetry and Cardiac Looping: Implications for Cardiac Development and Congenital Heart Disease. American Journal of Medical Genetics, 97, 271-279. https://doi.org/10.1002/1096-8628(200024)97:4<271::AID-AJMG1277>3.0.CO;2-O

[31] Trost, M. and Shimada, H. (2014) Hospitalists Should Have Increased Suspicion for Primary Ciliary Dyskinesia in Patients with Congenital Heart Disease. Hospital Pediatrics, 4, 109-112. https://doi.org/10.1542/hpeds.2013-0074

[32] Willaredt, M.A., Gorgas, K., Gardner, H.A. and Tucker, K.L. (2012) Multiple Essential Roles for Primary Cilia in Heart Development. Cilia, 1, 23. https://doi.org/10.1186/2046-2530-1-23

[33] Kuehl, K.S. and Loffredo, C.A. (2003) Population-Based Study of I-transposition of the Great Arteries. Possible Associations with Environmental Factors. Birth Defects Research. Part A. Clinical and Molecular Teratology, 67, 162-167. https://doi.org/10.1002/bdra.10015

[34] Feigenbaum, H., Armstrong, W.F. and Ryan, T. (2005) Feigenbaum's Echocardiography. $6^{\text {th }}$ Edition, Chapter 18, Congenital Heart Disease, Page 622, Figure 18.112, Saunders, Philadelphia, PA.

[35] Khoury, G.H. and Gilbert, E.E. (1970) Taussig-Bing Malformation with Coarctation of Aorta. Angiology, 21, 143. https://doi.org/10.1177/000331977002100301

[36] Parr, G.V.S., Waldhausen, J.A., Bharati, S., Lev, M., Fripp, R. and Whitman, V. (1983) Coarctation in Taussig-Bing Malformation of the Heart. Journal of Thoracic and Cardiovascular Surgery, 86, 280.

[37] Graham, et al. (2000) Long-Term Outcome in Congenitally Corrected Transposition of the Great Arteries. A Multi-Institutional Study. Journal of American College of Cardiology, 3, 255-261. https://doi.org/10.1016/S0735-1097(00)00682-3

[38] Dimas, A.P. Moodie, D.S. Sterba, R. and Gill, C.C. (1989) Long-Term Function of the Morphologic Right Ventricle in Adult Patients with Corrected Transposition of the Great Arteries. American Heart Journal, 118, 526-530. https://doi.org/10.1016/0002-8703(89)90268-8

[39] Presbitero, P., Somerville, J., Rabajoli, F., Stone, S. and Conte, M.R. (1995) Corrected Transposition of the Great Arteries without Associated Defects in Adult Patients: Clinical Profile and Follow Up. British Heart Journal, 74, 57-59. https://doi.org/10.1136/hrt.74.1.57

[40] Dyer, K. and Graham, T.P. (2003) Congenitally Corrected Transposition of the Great Arteries: Current Treatment Options. Current Treatment Options in Cardiovascular Medicine, 5, 399-407. https://doi.org/10.1007/s11936-003-0046-4

[41] Graham T.P., Markham, L., Parra, D.A. and Bichell, D. (2007) Congenitally Corrected Transposition of the Great Arteries. An Update. Current Treatment Options in Cardiovascular Medicine, 9, 407-413. https://doi.org/10.1007/s11936-007-0061-y

[42] Dore, A., Houde, C., Chan, K.L., Ducharme, A., Khairy, P., Juneau, M., Marcotte, F. and Mercier, L.A. (2005) Angiotensin Receptor Blockade and Exercise Capacity in Adults with Systemic Right Ventricles: A Multicenter, Randomized, Place- 
bo-Controlled Clinical Trial. Circulation, 112, 2411-2416. https://doi.org/10.1161/CIRCULATIONAHA.105.543470

[43] Shaddy, R.E., Boucek, M.M., Hsu, D.T., et al. (2007) Carvedilol for Children and Adolescents with Heart Failure. A Randomized Controlled Trial. JAMA (Journal of American Medical Association), 298, 1171-1179. https://doi.org/10.1001/jama.298.10.1171

[44] Lindenfeld, J., Keller, K., Campbell, D.N., Wolfe, R.R. and Quaife, R.A. (2003) Improved Systemic Ventricular Function after Carvedilol Administration in a Patient with Congenitally Corrected Transposition of the Great Arteries. The Journal of Heart and Lung Transplantation, 22, 198-201. https://doi.org/10.1016/S1053-2498(02)00656-3

[45] Jauvert, G., Rousseau-Paziaud, J., Villain, E., et al. (2009) Effects of Cardiac Resynchronization Therapy on Echocardiographic Indices, Functional Capacity, and Clinical Outcomes of Patients with a Systemic Right Ventricle. Europace, 11, 184-190. https://doi.org/10.1093/europace/eun319

[46] Khairy, P., Fournier, A., Thibault, B., Dubuc, M., Therien, J. and Vobecky, S.J. (2006) Cardiac Resynchronization Therapy in Congenital Heart Disease. International Journal of Cardiology, 109, 160-168. https://doi.org/10.1016/j.ijcard.2005.06.065

[47] Diller, G.P., Okonko, D., Uebing, A., Ho, S.Y. and Gatzoulis, M.A. (2006) Cardiac Resynchronization Therapy for Adult Congenital Heart Disease Patients with a Systemic Right Ventricle: Analysis of Feasibility and Review of Early Experience. Europace, 8, 267-272. https://doi.org/10.1093/europace/euj048

[48] Krishnan, K., Avramovitch, N.A., Kim, M.H. and Trohman, R.G. (2005) Cardiac Resynchronization Therapy: A Potential Option for Congenitally Corrected Transposition of the Great Vessels. The Journal of Heart and Lung Transplantation, 24, 2293-2296. https://doi.org/10.1016/j.healun.2005.05.011

[49] Warnes, C.A. (2006) Transposition of the Great Arteries. Circulation, 114, 2699-2709. https://doi.org/10.1161/CIRCULATIONAHA.105.592352

[50] Warnes, C.A. (2005) The Adult with Congenital Heart Disease: Born to be Bad? Journal of the American College of Cardiology, 46, 1-8. https://doi.org/10.1016/j.jacc.2005.02.083

[51] Hraska, V., Duncan, B.W., Mayer, J.E., Freed, M., Del Nido, P.J. and Jonas, R.A. (2005) Long-Term Outcome of Surgically Treated Patients with Corrected Transposition of the Great Arteries. Journal of Thoracic and Cardiovascular Surgery, 129, 182-191.

[52] Shin'oka, T., Kurosawa, H., Imai, Y., et al. (2007) Outcomes of Definitive Surgical Repair for Congenitally Corrected Transposition of the Great Arteries or Double Outlet Right Ventricle with Discordant Atrioventricular Connections: Risk Analyses in 189 Patients. Journal of Thoracic and Cardiovascular Surgery, 133, 1318-1328. https://doi.org/10.1016/j.jtcvs.2006.11.063

[53] Van Son, J.A., Danielson, G.K., Huhta, J.C., et al. (1995) Late Results of Systemic Atrioventricular Valve Replacement in Corrected Transposition. Journal of Thoracic and Cardiovascular Surgery, 109, 642-652. https://doi.org/10.1016/S0022-5223(95)70345-4

[54] Scherptong, R.W., Vliegen, H.W., Winter, M.M., et al. (2009) Tricuspid Valve Surgery in Adults with a Dysfunctional Systemic Right Ventricle: Repair or Replace? Circulation, 119, 1467-1472. https://doi.org/10.1161/CIRCULATIONAHA.108.805135 
[55] Ilbawi, M.N., DeLeon, S.Y., Backer, C.L., et al. (1990) An Alternative Approach to the Surgical Management of Physiologically Corrected Transposition with Ventricular Septal Defect and Pulmonary Stenosis or Atresia. Journal of Thoracic and Cardiovascular Surgery, 100, 410-415.

[56] Hraska, V., Mattes, A., Haun, C., et al. (2011) Functional Outcome of Anatomic Correction of Corrected Transposition of the Great Arteries. European Journal of Cardiothoracic Surgery, 40, 1227-1234.

[57] Shim, M.S., Jun, T.G., Young, J.H., et al. (2017) Clinical Outcomes after Anatomic Repair including Hemi-Mustard Operation in Patients with Congenitally Corrected Transposition of the Great Arteries. Korean Circulation Journal, 47, 201-208. https://doi.org/10.4070/kcj.2016.0194

[58] Lee, C.-H., Choi, E.S., Cho, S. and S.-J. Park (2017) Anatomic Repair including Hemi-Mustard in Congenitally Corrected Transposition of the Great Arteries. What We Know and Still Need to Know. Korean Circulation Journal, 47, 173-175. https://doi.org/10.4070/kcj.2017.0001

[59] Marathe, S.P., Jones, M.I., Ayer, J., Sun, J., Orr, Y., Verrall, C., Nicholson, I.A., Chard, R.B., Sholler, G.F. and Winlaw, D.S. (2017) Congenitally Corrected Transposition: Complex Anatomic Repair or Fontan Pathway? Asian Cardiovascular \& Thoracic Annals, 25, 432-439. https://doi.org/10.1177/0218492317717412

[60] Hsu, K.H., Chang, C.I., Huang, S.C., Chen, Y.S. and Chiu, I.S. (2016) 17-Year Experience in Surgical Management of Congenitally Corrected Transposition of the Great Arteries: A Single-Center's Experience. European Journal of Cardiothoracic Surgery, 49, 522-527. https://doi.org/10.1093/ejcts/ezv148

[61] Wu, Q.-Y., Li, Hi, D.H., Li, H.-Y., Zhang, M.-K., Xu, Z.-H. and Xue, H. (2017) Surgical Treatment of Double Outlet Right Ventricle Complicated by Pulmonary Hypertension. Chinese Medical Journal, 130, 409-413. https://doi.org/10.4103/0366-6999.199827

[62] Metton, O., Gaudin, R., Ou, P., et al. (2010) Early Prophylactic Pulmonary Artery Banding in Isolated Congenitally Corrected Transposition of the Great Arteries. European Journal of Cardiothoracic Surgery, 38, 728-734. https://doi.org/10.1016/j.ejcts.2010.03.065

[63] Kleinnert, S., Sano, T., Weintraub, R.B., et al. (1997) Anatomic Features and Surgical Strategies in Double-Outlet Right Ventricle. Circulation, 96, 1233-1239. https://doi.org/10.1161/01.CIR.96.4.1233

[64] Williams, W.G., Freedom, R.M., Culham, G., et al. (1981) Early Experience with Arterial Repair of Transposition. Annals of Thoracic Surgery, 32, 8-15. https://doi.org/10.1016/S0003-4975(10)61364-1

[65] Yacoub, M.H. and Radley-Smith, R. (1984) Anatomic Correction of the Taussig-Bing Anomaly. Journal of Thoracic and Cardiovascular Surgery, 88, 380-388.

[66] Ceithaml, E.L., Puga, F.J., Danielson, G.K., McGoon, D.C. and Ritter, D.G. (1984) Results of the Damus-Stansel-Kaye Procedure for Transposition of the Great Arteries and for Double-Outlet Right Ventricle with Subpulmonary Ventricular Septal Defect. Annals of Thoracic Surgery, 38, 433-437. https://doi.org/10.1016/S0003-4975(10)64180-X

[67] Serraf, A., Lacour-Gayet, F., Bruniaux, J., et al. (1991) Anatomic Repair of Taussig-Bing hearts. Circulation, 84, 200-205.

[68] Sakata, R., Lecompte, Y., Batisse, A., Borromee, L. and Durandy, Y. (1988) Anatomic Repair of Anomalies of Ventriculoarterial Connection Associated with Ventricular Septal Defect. I. Criteria of Surgical Decision. Journal of Thoracic and Car- 
diovascular Surgery, 95, 90-85.

[69] Gewiling, M. and Goldberg, D.J. (2014) Failure of the Fontain. Circulation, 10, 105-116.

[70] Lundstrom, U., Bull, C., Wyse, R.K., et al. (1990) The Natural and Unnatural History of Congenitally Corrected Transposition of the Great Arteries. American Journal of Cardiology, 65, 1222-1229. https://doi.org/10.1016/0002-9149(90)90978-A

[71] Oliver, J.M., Gallego, P., Gonzalez, A.E., Sanchez-Recalde, A., Brett, M., Polo, L. and GutIerrez-Larraya, F. (2012) Comparison of Outcomes in Adults with Congenitally Corrected Transposition with Situs Inversus versus Situs Solitus. American Journal of Cardiology, 110, 1687-1691. https://doi.org/10.1016/j.amjcard.2012.07.039

[72] Hill, M. (2017) Cardiovascular System-Double Outlet Right Ventricle. UNSW (University of New South Wales) Embryology, 24 October.

[73] Rodefeld, M.D., Ruzmetov, M., Vijay, P., Fiore, A.C., Turrentine, M.W. and Brown, J.W. (2007) Surgical Results of Arterial Switch Operation for Taussig-Bing Anomaly: Is Position of the Great Arteries a Risk Factor? Annals of Thoracic Surgery, 83, 1451-1457. https://doi.org/10.1016/j.athoracsur.2006.10.072

[74] Alsoufi, B., Cai, S., Williams, W.G., Coles, J.G., Caldarone, C.A., Redington, A.M. and Van Arsdell, G.S. (2008) Improved Results with Single-Stage Total Correction of Taussig-Bing Anomaly. European Journal of Cardiothoracic Surgery, 33, 244-250. https://doi.org/10.1016/j.ejcts.2007.11.017

[75] Siman, C.M., Gittenberger-De Groot, A.C., Wisse, B. and Eriksson, U.J. (2000) Malformations in Offspring of Diabetic Rats: Morphometric Analysis of Neural Crest-Derived Organs and Effects of Maternal Vitamin E Treatment. Teratology, 61, 355-367.

https://doi.org/10.1002/(SICI)1096-9926(200005)61:5<355::AID-TERA7>3.0.CO;2-W 